\title{
Precios, ratios y costes en la prestación de servicios residenciales para personas mayores: análisis comparativo entre Gipuzkoa y el resto del Estado
}

\author{
Alejandro Gómez Ordoki \\ Lares Euskadi \\ lares@lareseuskadi.org
}

\begin{abstract}
Adineko pertsonentzako egoitzetako azpisektorearen azken hamarkadetako eboluzioa oso desberdina izan da Estatuko autonomiaerkidegoetan. Hori gertatu da politika sozial desberdinek garatu dituztelako homologazio eta akreditaziorako askotariko arauak, eta Estatuko mapak itxurazko nahaste eta sakabanatzearen tankera hartu du, eta ematen du Konstituzioak agindutako lurraldeen arteko elkartasuna ez dela betetzen. Halere, plano simetriko eta alternatibo batean, adibidez, gizarte-laguntza bezalako arloetako eskuduntzak hartu dituzte autonomia-erkidego horiek. Bi bektore horiek ez dute norantza berean eragiten, eta ematen du errealitatearen azterketa sinplista bat eta aldagai desberdinen arteko korrelaziorik gabekoa ez dela nahikoa sakabanatzearen ideiari eusteko. Artikulu honetan neurtu nahi da hautemate sinplista hori, eta horretarako erabiltzen da salneurri, ratio, langileen orduen kostu eta funtzionamendu eta amortizaziorako kostu estandarizatuak oinarri duen ikuspegi bat.
\end{abstract}

\section{GAKO-HITZAK:}

Personas mayores, residencias, dependencia, tarifas, coste/plaza, personal.
La diferente evolución experimentada por el subsector de las residencias para personas mayores durante las últimas décadas en las distintas comunidades autónomas del Estado, consecuencia de la aplicación de políticas sociales independientes desde las que desarrollar normas propias de homologación y acreditación de geriátricos, ha desembocado en un mapa estatal de servicios residenciales aparentemente disperso e inconexo y que parece no respetar el principio de solidaridad interterritorial promulgado por la Constitución. En un plano simétrico y alternativo, sin embargo, las comunidades autónomas asumen competencias en materias como la asistencia social. Ambos vectores no parecen aplicar su fuerza en una misma dirección y un análisis de la realidad simplista y carente de correlaciones entre diferentes variables podría no bastar para explicar una idea de dispersión probablemente no contrastada desde diferentes perspectivas. Este artículo pretende ponderar esta percepción simplista desde el análisis de las posibles correlaciones entre precios, ratios, coste/hora de personal y costes estandarizados de funcionamiento y amortización.

\section{Palabras Clave}

Personas mayores, residencias, dependencia, tarifas, coste/plaza, personal. 


\section{Introducción: contexto, metodología y terminología}

En el Estado español coexisten tres sistemas diferenciados de financiación autonómica, dos de ellos como consecuencia del reconocimiento explícito de los derechos históricos al amparo de la Disposición Adicional Primera de la Constitución de 1978 (el Concierto Económico del País Vasco y el Convenio Económico en la Comunidad Foral de Navarra) y uno de aplicación generalizada o régimen común por el que se rigen el resto de comunidades. Sin entrar a valorar los condicionantes políticos implícitos en la aplicabilidad de sendos sistemas, es cierto que la facultad reconocida a Euskadi para recaudar impuestos con los que financiar los gastos necesarios para la prestación de servicios públicos origina una idiosincrasia propia en el desarrollo de políticas garantistas del Estado de Bienestar: sanidad, educación y servicios sociales. Por la Ley 27/1983 del Parlamento Vasco, también conocida como Ley de Territorios Históricos, se atribuyen determinadas competencias a cada una de las diputaciones forales de Araba, Bizkaia y Gipuzkoa, lo que, a su vez, particulariza los sistemas de servicios sociales en cada territorio, si bien prevalece un marco superior de regulación que compete exclusivamente al Gobierno Vasco. Un ejemplo claro de esta mecánica administrativa es la gestión de las redes residenciales para personas mayores: el Parlamento Vasco aprueba leyes y decretos como el Decreto 41/1998 sobre servicios sociales residenciales para la tercera edad -actualmente en proceso de sustitución- pero son los gobiernos forales los encargados de gestionar aspectos tan variados como el precio público, el copago, las listas de espera o, incluso, la definición de ratios por encima de las establecidas por la norma autonómica de referencia (Decreto Foral 38/2007, por el que se determinan las condiciones necesarias para la concertación de servicios residenciales para personas mayores dependientes en Gipuzkoa). En un contexto como el descrito, no sorprende que la supuesta dispersión en las normativas del conjunto del Estado español se reproduzca en Euskadi con mayores diferencias si cabe. El estudio en el que se basa este artículo no trata de demostrar que la realidad asistencial es ciertamente heterogénea; su objetivo fundamental es poner en relieve que el marco regulador sí lo es y que, por ello, la evolución de las organizaciones prestadoras de servicios residenciales no ha confluido en modelos de atención uniformes ni tan siquiera como consecuencia de la permanente adaptación de los recursos a las necesidades. Como en otros sectores, también en el nuestro las líneas evolutivas entre la legislación aplicable y los recursos requeridos por perfiles de atención progresivamente más demandantes tienden claramente hacia la divergencia.

El estudio presenta tres partes diferenciadas en su metodología de desarrollo: mapa de precios y ratios, estimación de estructuras de coste en función de las normativas autonómicas y extrapolación del modelo de Gipuzkoa al resto de comunidades. La primera de las partes pretende describir la información referente a precios y ratios del conjunto de normativas de aplicación en el Estado, a la par que ofrece gráficos con criterio de orden a la hora de ubicar a cada autonomía/territorio con respecto a las demás, para avanzar una idea de cierta convergencia que termina por desvanecerse. En la sección central del estudio, el objetivo es ponderar cada factor de coste (personal en función de las ratios para diferentes niveles de dependencia, gastos estandarizados de funcionamiento y dotaciones a la amortización corregidas para cada autonomía en función del coste del metro cuadrado de construcción) para comprobar hasta qué punto las normativas posibilitan la obtención teórica de mayores márgenes de beneficio en determinadas autonomías/territorios. Finalmente, una vez realizado un análisis de sensibilidad entre la ratio total de personal y el precio en Gipuzkoa que demuestra la correspondencia entre ambas variables, proyectaremos su estructura al resto de comunidades para estimar precios y costes en un intento de modular los recursos necesarios para la prestación del servicio. Asimismo, la parte final del estudio plantea un procedimiento teórico para la adaptabilidad del modelo guipuzcoano al resto de normativas del Estado.

La dispersión también es un hecho contrastado desde el uso de muy variados descriptores del nivel de dependencia. La estandarización de términos debe superar ciertos anacronismos y homologar los perfiles conforme a baremos oficiales y, por tanto, de aplicación obligada en el ámbito de la dependencia. Así, para la graduación prevista en el Baremo de Valoración de la Dependencia (BVD) se establecen las relaciones unívocas que muestra la Figura 1.

Figura 1. Asociaciones entre descriptores y grados del Baremo de Valoración de la Dependencia (BVD)
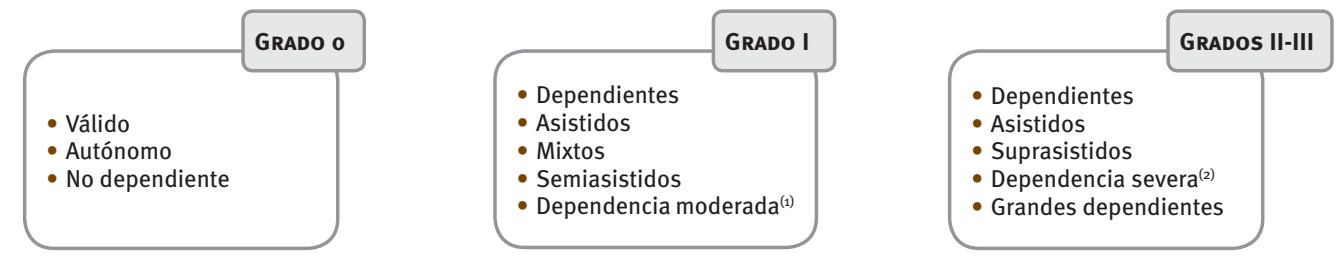

(1) y (2): se podrían colocar indistintamente en grados I y II-III porque muchas normativas solo discriminan dependencia y no dependencia. 


\section{Presumible dispersión inicial: precio y ratios de personal}

En una primera aproximación, la sensación inmediata es que la homogeneidad en precios no es una característica del sector. En efecto, desde el análisis de los datos comparativos entre las diferentes normativas aplicables en cada territorio administrativo - básicamente hemos navegado exhaustivamente por internet para la búsqueda de decretos reguladores a falta de documentos específicos e inexistencia o, al menos, desconocimiento de bases de datos sujetas a actualizaciones permanentes- concluimos que la dispersión se apodera de la realidad. A la relativamente baja correlación entre ratios de gerocultor/a y precio/plaza ( $r$ de Pearson de 0,633 para el conjunto de normativas que distinguen este tipo de ratio) se unen diferencias cualitativas en la identificación de los perfiles de atención o grados de dependencia (autonomías que no discriminan junto a otras que lo hacen con criterios dispares) y en la definición de límites de copago por omisión de precios públicos. Mientras algunas comunidades autónomas distinguen precios por perfiles sin hacer lo propio con su normativa reguladora, otras pagan tarifas únicas cuando en la práctica detallan ratios por categorías de atención.

Del total de autonomías y territorios con competencias para normativizar en la atención residencial a personas mayores (dieciséis comunidades y los tres territorios históricos de Euskadi), algo más de tres cuartas partes (el 79\%) definen algún coste por plaza o precio público; del $21 \%$ restante no podemos afirmar, sin embargo, que las Administraciones no intervengan en la definición de precios, dado que obligan a las entidades concertadas o contratadas a definirlos públicamente. Si bien los requerimientos sobre cumplimiento de ratios son taxativos, la limitación del coste/plaza o precio público no es tan clara. Además, las diferentes alternativas para la financiación pública de las plazas en reserva o no ocupadas (por ejemplo, Gipuzkoa reconoce dichas plazas en un $75 \%$ de su coste teórico y La Rioja en un $50 \%$, cuando la norma más extendida en el Estado es no abonar cantidad alguna por las plazas vacantes o reservadas), viene a incrementar la idea de dispersión y escasa uniformidad del sector. Como último elemento distorsionador, las tasas de cobertura pública (total de plazas privadas concertadas o contratadas) tampoco se presentan en condiciones de homogeneidad y concentración. Así, mientras Gipuzkoa concierta un $87,7 \%$ de las plazas acreditadas en su territorio, la media del Estado se sitúa en poco menos de un $50 \%$ de media ( $L a$ situación de los centros residenciales para personas mayores en Gipuzkoa, SIIS, 2016, tabla 5).

Si por algo se caracteriza el mapa de ratios para residencias de personas mayores en el Estado es, precisamente, por la variedad de perspectivas empleadas en la definición o cuantificación de los recursos humanos. Indistintamente se van sucediendo normativas que, en algunos casos, concretan las ratios sin especificar qué categorías profesionales subyacen tras ellas y, en otros, detallan su composición cualitativa sin medir su presencia concreta. Así, podemos encontrarnos con panoramas tan dispersos como los descritos a continuación:

- Comunidad Valenciana (ejemplo de autonomía con despliegue a máximo nivel): discrimina tres tipologías de plazas con asignación "simétrica” de ratios 0 , al menos, pautas de cálculo para cada categoría profesional concretando, además, las categorías profesionales integrantes de la atención directa e indirecta. Ratios y precios, sin embargo, no se ajustan a una misma distribución de perfiles de atención (personas mayores versus válidas, personas mayores dependientes versus semiasistidas y unidades de alta dependencia versus asistidos-suprasistidos).

- La Rioja (normativa que clasifica sin considerar tipologías de atención): agrupa las residencias por categoría que, a su vez, dependen del tamaño o capacidad asistencial. Si bien detalla la composición del personal de atención directa (médico, ATS/DUE, auxiliar sanitario, trabajador social, fisioterapeuta y terapeuta ocupacional) nada dice del personal de atención indirecta. En todo caso, no es sensible al perfil de dependencia y escalona las necesidades de personal en función de intervalos asistenciales (capacidad del centro).

- Navarra (paradigma de la simplicidad): ratios totales ajustadas a la dualidad válido-asistido que no pormenorizan nada y que únicamente exige la presencia permanente de DUE para residencias de asistidos.

Si interpretemos los datos contenidos en las Tablas 1 y 2, observamos que no todas las normativas definen precios en la misma medida para los diferentes grados de dependencia (79\% para el grado I, $63 \%$ para los grados II y III, y $58 \%$ para el grado o). Asimismo, podemos escalonar la definición de ratios, una vez respetadas las relaciones de la Figura 1, conforme a la siguiente distribución: el $86 \%$ de las normativas definen algún tipo de ratio (gerocultor/a, directa o total) para el grado o, el $95 \%$ para el grado I y tan solo un $29 \%$ para los grados II y III. Es innegable que una lectura basada exclusivamente en el valor del precio público para cada nivel de dependencia es absolutamente concluyente: Gipuzkoa y Bizkaia liderarían el panorama estatal y, en consecuencia, se les supondría mayor potencial para la prestación del servicio que al resto de comunidades. Una hipótesis que, en todo caso, deberíamos demostrar desde un análisis más complejo de la realidad para dar respuesta a la secuencia cuánto-para qué. En otras palabras, si se comprobara, por ejemplo, una correlación efectiva entre precio y ratio total, podríamos descubrir una primera justificación de la diferencia en precio, por otra parte ni única ni exclusiva (como más adelante 
se demuestra, la tendencia a establecer relaciones directas entre precio y ratio total no alcanza la suficiente consistencia como para verificar que cada autonomía fija sus precios en función de las ratios).

Como indicamos, la disparidad de criterios se acentúa aún en mayor medida si contrastamos la correspondencia entre los perfiles de dependencia en la definición de ratios -que, además, intentan representar bajo una misma acepción teórica toda una amalgama de conceptos heterogéneos como asistidos, válidos, semiválidos, suprasistidos, mixtos, grados, moderados y un largo etcétera de descriptores-y los perfiles de dependencia para identificar grupos de coste o precio público, aunque se vislumbre cierta tendencia a concentrar la valoración de la dependencia conforme a un baremo comúnmente extendido (fundamentalmente el BVD, con un $80 \%$ de prevalencia sobre el abanico de escalas y baremos utilizados). En todo caso, solo Gipuzkoa y la Comunidad de Valencia presentan una igualdad simétrica entre ratio y grupo de coste, si bien valoran la dependencia desde diferentes escalas (BVD en Gipuzkoa y escala Barthel en la Comunidad de Valencia) y especifican ratios para ella con diferente nivel de detalle (mientras la Comunidad de Valencia lo hace para las ratios de atención directa, Gipuzkoa pormenoriza ratios de atención directa para el

Tabla 1. Precios por plaza por autonomía (territorio en Euskadi)

\begin{tabular}{|c|c|c|}
\hline Comunidad & Perfil & $€$ \\
\hline \multirow{4}{*}{ Gipuzkoa } & Autónomos (resto) & 61,04 \\
\hline & Grado I & 74,42 \\
\hline & Grado II y III & 93,22 \\
\hline & Psicogeriátricas & 100,6 \\
\hline \multirow{3}{*}{ Andalucía } & Válidas & 26,83 \\
\hline & Asistidos & 49,57 \\
\hline & $\begin{array}{l}\text { Graves y continuados trastornos del } \\
\text { comportamiento }\end{array}$ & 63,5 \\
\hline Araba & No distingue perfil & 42,2 \\
\hline \multirow{3}{*}{ Aragón } & Válidos & 26,07 \\
\hline & Asistidos & 48,81 \\
\hline & $\begin{array}{l}\text { Personas mayores dependientes con } \\
\text { alteraciones graves de conducta }\end{array}$ & 75,84 \\
\hline \multirow{3}{*}{ Asturias } & No dependiente & 41,95 \\
\hline & Grado I & 41,95 \\
\hline & Grado II-III & 45,62 \\
\hline \multirow{2}{*}{ Bizkaia } & Válidas y asistidas & 77,88 \\
\hline & Alta complejidad de cuidados & 81,73 \\
\hline \multicolumn{3}{|l|}{ Canarias } \\
\hline \multirow[t]{2}{*}{ Cantabria } & Dependencia moderada y severa & 43,69 \\
\hline & Gran dependencia & 52,83 \\
\hline \multirow{3}{*}{$\begin{array}{l}\text { Castilla - La } \\
\text { Mancha }\end{array}$} & No dependiente & 33 \\
\hline & Grado I & 42 \\
\hline & Grado II-III & 48 \\
\hline \multirow{4}{*}{ Castilla y León } & No dependiente & 30,72 \\
\hline & Dependiente & 43 \\
\hline & Gran dependiente & 49,15 \\
\hline & Psicogeriátricas & 57,43 \\
\hline
\end{tabular}

Fuente: Elaboración propia. conjunto de categorías profesionales); para el resto de comunidades, la desigualdad es una constante.

Salvo Canarias y Cantabria para perfiles de grado o en ratio y Canarias, Extremadura y Madrid para precios en cualquier grado de dependencia, todas las comunidades contemplan pares combinados de precio y alguna categoría de ratio (total, directo y/o gerocultor/a). No obstante, apenas hay simetría entre la identificación de perfiles de atención y la asignación de precios de referencia. La asimetría es tal que únicamente Gipuzkoa y Valencia presentan paralelismo entre ambos conceptos aunque de manera dispar: para Gipuzkoa la correspondencia es directa (se realiza sobre grupos de dependencia según el BVD); en cambio, Valencia necesita interpretar la correlación de acuerdo con las relaciones de la Figura 1.

Hasta el momento, las descriptivas analizadas de precio y ratios configuran un contexto enmarcado por la dispersión. Aun cuando algunas ratios repitan su valor para diferentes normativas, los precios no siguen idéntica tónica y consecuentemente se antoja improbable una correspondencia mínima entre ambas variables. Obtengamos, en cualquier caso, los coeficientes de correlación para todos los pares de valores de precio y ratio, que se reflejan en la Tabla 3.

\begin{tabular}{|c|c|c|}
\hline Comunidad & Perfil & $€$ \\
\hline \multirow{3}{*}{ Cataluña } & No dependiente & 27,85 \\
\hline & Grado I & 52,44 \\
\hline & Grado II-III & 61,46 \\
\hline \multicolumn{3}{|l|}{ Extremadura } \\
\hline Galicia & Grados II y III & 48,08 \\
\hline \multirow{4}{*}{ Islas Baleares } & Grado I & 58,6 \\
\hline & Grado II & 62,08 \\
\hline & Grado III & 66,04 \\
\hline & $\begin{array}{l}\text { Servicio residencial especializado } \\
\text { para personas mayores }\end{array}$ & 111,8 \\
\hline \multirow{2}{*}{ La Rioja } & Dependientes severos & 60,14 \\
\hline & Grandes dependientes & 77,36 \\
\hline \multicolumn{3}{|l|}{ Madrid } \\
\hline \multirow{2}{*}{ Murcia } & Dependientes & 52,6 \\
\hline & Psicogeriátricas & 59,18 \\
\hline \multirow{4}{*}{ Navarra } & No dependientes & 24,95 \\
\hline & Dependencia moderada & 45,76 \\
\hline & Dependencia severa & 48,02 \\
\hline & Gran dependencia & 50,28 \\
\hline \multirow{3}{*}{ Valencia } & Válidos y semiasistidos & 38,93 \\
\hline & Asistidos & 47,28 \\
\hline & Suprasistidos & 52,6 \\
\hline
\end{tabular}


Tabla 2. Ratios en función de la secuencia gerocultor/a $\rightarrow$ atención directa $\rightarrow$ atención total ${ }^{(1)}$

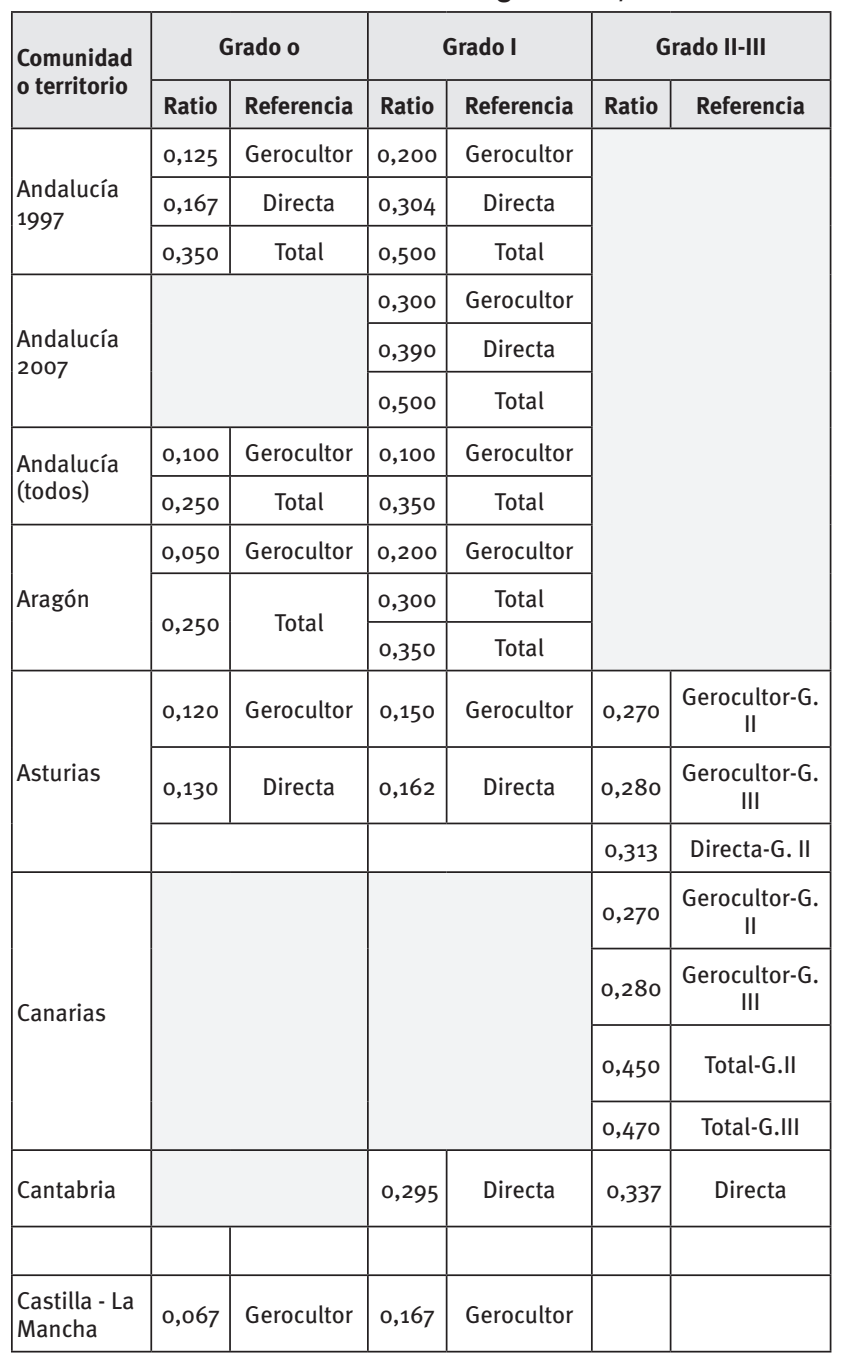

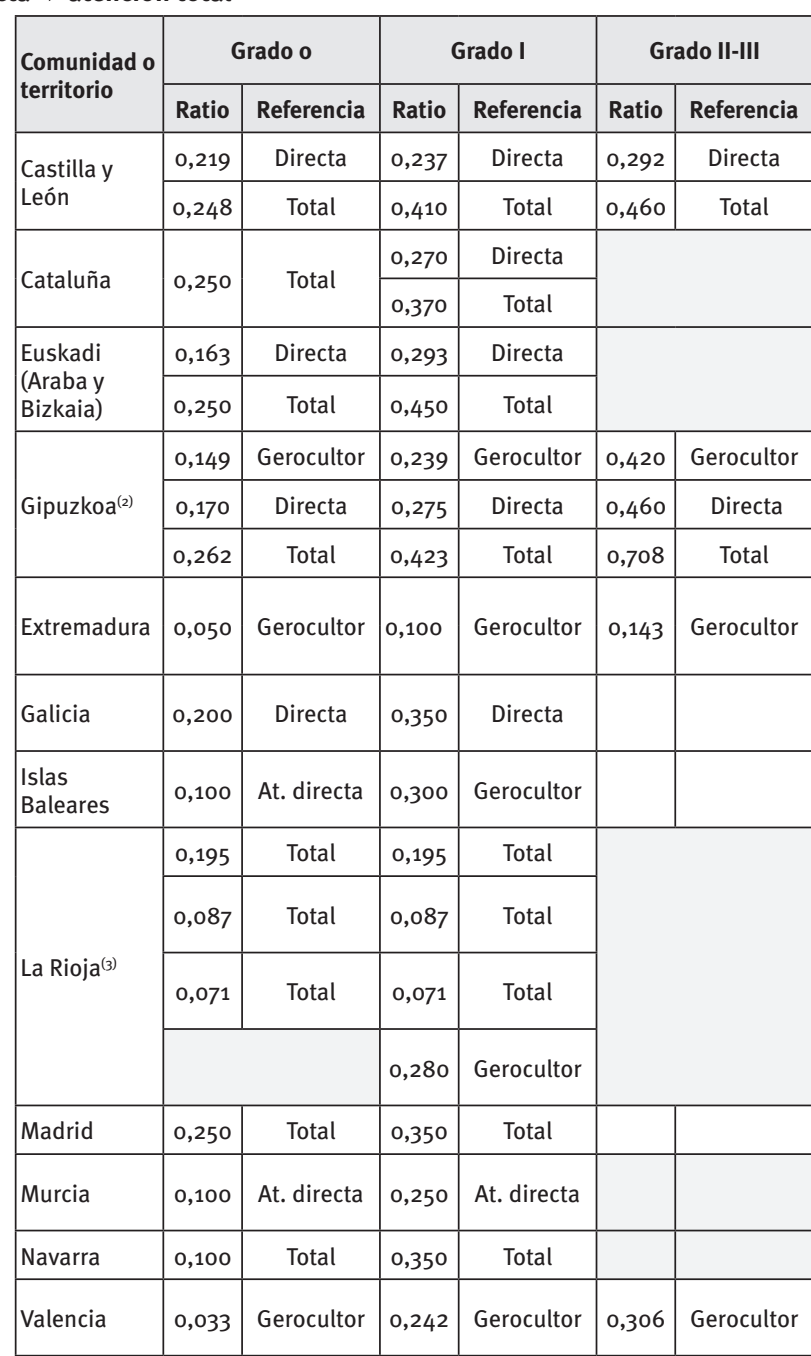

(1) La antigüedad media de las normativas es de 15,7 años, con una desviación estándar de 7,6 años. Madrid (27,3), Navarra (26,7) y Aragón (25,7) lideran el ranking de normas cuasi obsolescentes; Castilla y León cuenta con la norma más joven de apenas dos años de vigencia.

(2) Por la Ley de Territorios Históricos, Ley 27/1983, Gipuzkoa asume determinadas competencias en materia de financiación de residencias de personas mayores y, en consecuencia, regula también la actividad desde el Decreto Foral 38/2007.

(3) La ratio de auxiliar de geriatría se define como la ratio media entre las cotas inferior y superior del intervalo correspondiente. Se definen tres intervalos (1-40, 41-200 y $\mathbf{2 0 0}$ ) porque las medias de los intervalos intermedios (41-75, 75-150 y 151-200) son prácticamente iguales. Se referencian ratios para esta comunidad a efectos meramente informativos porque no discrimina categorías de dependencia.

Fuente: Elaboración propia/Lares Federación, Los requisitos de acreditación para residencias de personas mayores (Molina, 2010).

Tabla 3. Coeficiente $r$ de Pearson entre precio-ratio

\begin{tabular}{|l|c|c|c|c|}
\hline \multirow{2}{*}{ Comparativa } & \multicolumn{4}{|c|}{ Perfil de residente } \\
\cline { 2 - 5 } & Grado o & Grado I & Grados II y III & Total \\
\hline Sobre ratios específicas de gerocultor/a & 0,5370 & 0,4711 & 0,7765 & 0,7637 \\
\hline Sobre ratios de atención directa & $-0,1475$ & 0,1980 & 0,9782 & 0,4219 \\
\hline Sobre ratio total & 0,3320 & 0,4163 & 0,9560 & 0,6351 \\
\hline
\end{tabular}

Fuente: Elaboración propia. 


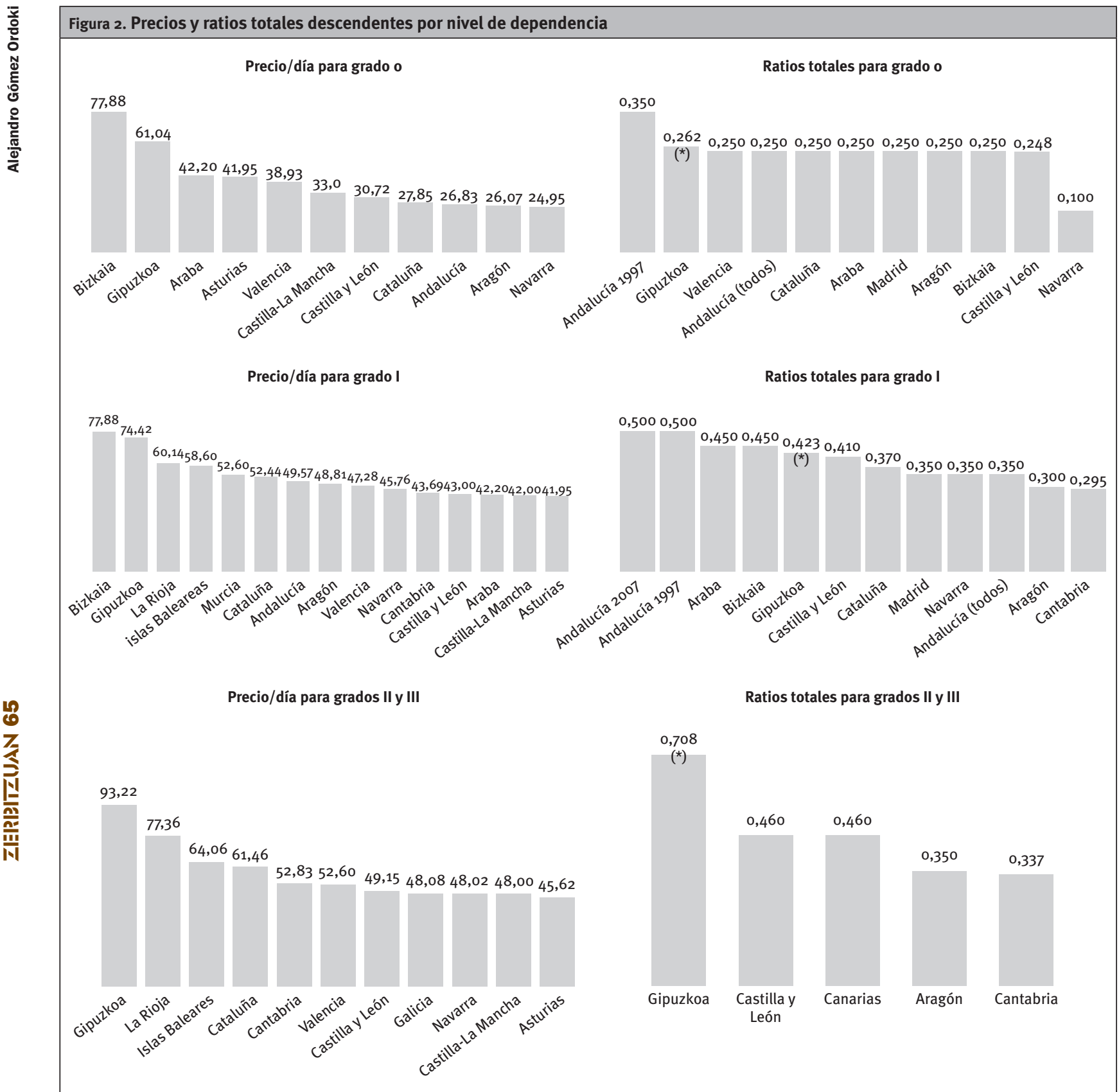

${ }^{(*)}$ Ratios obtenidas aplicando a las ratios directas del Decreto 38/2017 la relación 0,35/0,65 entre atención indirecta y directa del Decreto 41/98 del Gobierno Vasco.

Fuente: Elaboración propia.

La máxima correlación entre precio y ratio se presenta para los grados II-III y, especialmente, para la ratio de atención directa con un coeficiente $r$ de Pearson igual a 0,9782. Cuando la correlación es para el conjunto de precios asociados a la ratio total para cada nivel de dependencia, el coeficiente baja hasta 0,6351 . En algunos casos, estos valores podrían adelantar una idea que cuestionara la supuesta heterogeneidad del sector en la medida en que la relación entre precio y ratio no puede catalogarse de nula o escasa consistencia, aunque ciertos pares se sitúen ciertamente alejados del teórico marcado por la recta de regresión (Figura 3). Si -como ocurre en prácticamente todos los casos - a medida que crece el nivel de dependencia aumenta la correlación, solo en aquellas normativas que distinguen precios para grados superiores y en la media que el índice ponderado de dependencia - en adelante IPD- se aproxime a su máximo valor (IPD $=\frac{n_{1}+2^{\star} n_{2}+3^{*} n_{3}}{n}$, donde $n_{i}$ es el número de residentes de cada grado de dependencia y $n$ es la capacidad máxima del centro, que será igual a $\sum_{i=1}^{i=3} n_{i}$ para una ocupación plena), el precio podría ser función directa de la ratio de atención. Esta posibilidad, sin embargo, parece ser exclusiva de normativas como la de Gipuzkoa, Castilla y León o Cantabria. 


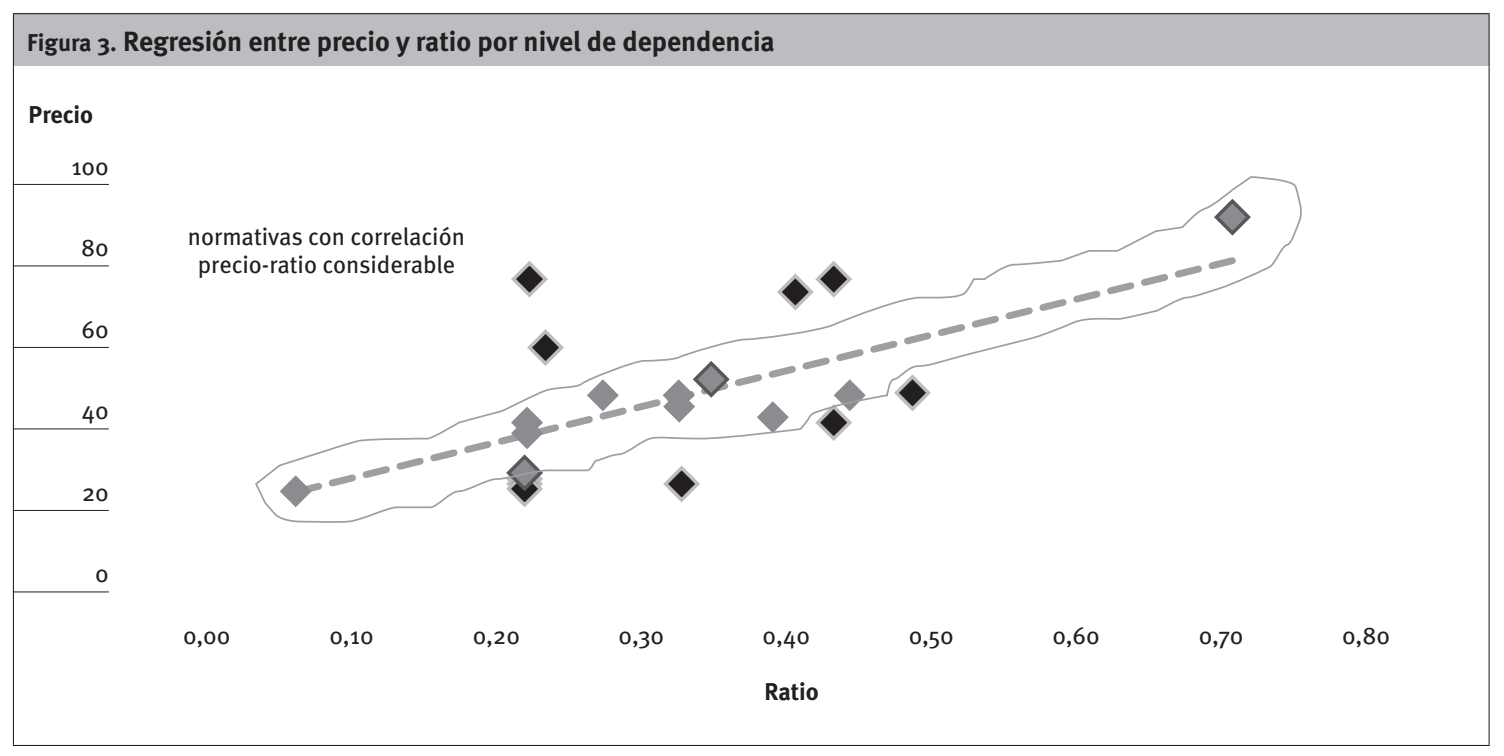

Fuente: Elaboración propia.

El contenido de las normativas reguladoras refleja que la evolución experimentada por cada autonomía no ha seguido patrón alguno. Aun cuando el marco legal delimite el disfrute de derechos subjetivos individuales en igualdad de condiciones en todas y cada una de las comunidades del Estado, las directrices en políticas sociales no emanan de un ente supracomunitario y en esa particularidad configuran distintas garantías en el cumplimiento de los referidos derechos. La Ley 39/2006 de Promoción de la Autonomía Personal y Atención a las personas en situación de dependencia no particulariza su aplicación en función de las potencialidades de cada autonomía y, sin embargo, el nivel y calidad de su despliegue en las comunidades del Estado es reflejo de la importancia que para cada gobierno autónomo o local representa el denominado tercer sector. En este sentido, la Asociación Estatal de Directores y Gerentes en Servicios Sociales (Observatorio Estatal para la Dependencia) ha publicado recientemente un ranking encabezado por cuatro ayuntamientos vascos como excelentes en inversión social (Errenteria, Santurtzi, Arrasate-Mondragón y Eibar), todos ellos con montantes superiores a 200 euros por habitante y año. Así, el desarrollo reglamentario de aquellas competencias transferidas a las comunidades autónomas ha originado, por ejemplo, que las normativas reguladoras de la atención residencial a personas mayores se caractericen por presentar una realidad totalmente incongruente. Pero no por ello - como demostraremos en el análisis de la estructura del coste por plaza-debemos ser tan ingenuos como para sentenciar que aquellas comunidades con mayores precios públicos son las que aseguran mayores rentabilidades en la gestión de este tipo de centros. También en esta materia la dispersión se constituye en un rasgo distintivo del sector.

Gipuzkoa destaca claramente sobre las demás en la pormenorización de su normativa. Obsérvese a este respecto la situación tan alejada que ocupan los otros dos territorios históricos que constituyen la comunidad autónoma del País Vasco: Bizkaia (7,9 puntos) y Araba (7,6 puntos). La razón de este gap no es otra que la posibilidad de implementar modelos de atención residencial singularizados en cada territorio histórico (Ley 27/1983 del Parlamento Vasco y Decreto Foral 38/2007 versus Decreto 41/1998). Especialmente significativa es la pobreza que presentan normativas correspondientes a comunidades con capacidades presumibles muy por encima de lo que refleja su puntuación en el baremo (Madrid, con tan solo 2,7 puntos).

Si en algo despunta Gipuzkoa sobre casi la totalidad del resto de comunidades es en el valor que alcanzan sus ratios, cualquiera que sea el grado de dependencia. Pero no lo hace en la misma medida que pudieran indicar los valores absolutos de dichas ratios. El convenio colectivo de referencia en Gipuzkoa establece una jornada anual de 1.592 horas, condición que contrae la supuesta diferencia a menores términos. Comparemos para las diferentes normativas y para las distintas ratios que fijan bajo qué circunstancias (valores de IPD) Gipuzkoa ofrece un modelo de atención con mayor número de horas de personal (simulación en un centro de 100 plazas en el que se combinan residentes de grados 0 , I y II-III a intervalos de 10).

En términos generales, la normativa de Gipuzkoa (Decreto Foral 38/2007) está por encima del resto de comunidades del Estado en un 80,5\% de las combinaciones simuladas de grados 0 , I y II-III. La distribución por tipo de ratio también confirma esta patente superioridad $(78,7 \%$ para ratio totales, $68,2 \%$ para atención directa y $97,1 \%$ para ratio de gerocultor/a) que llega a convertirse en un suceso cuasi seguro para IPD iguales o superiores a 2,5 (en el $98,9 \%$ de los casos, la propuesta de Gipuzkoa se impone). 
Tabla 4. Nivel de detalle de las normativas reguladoras de la atención residencial a personas mayores

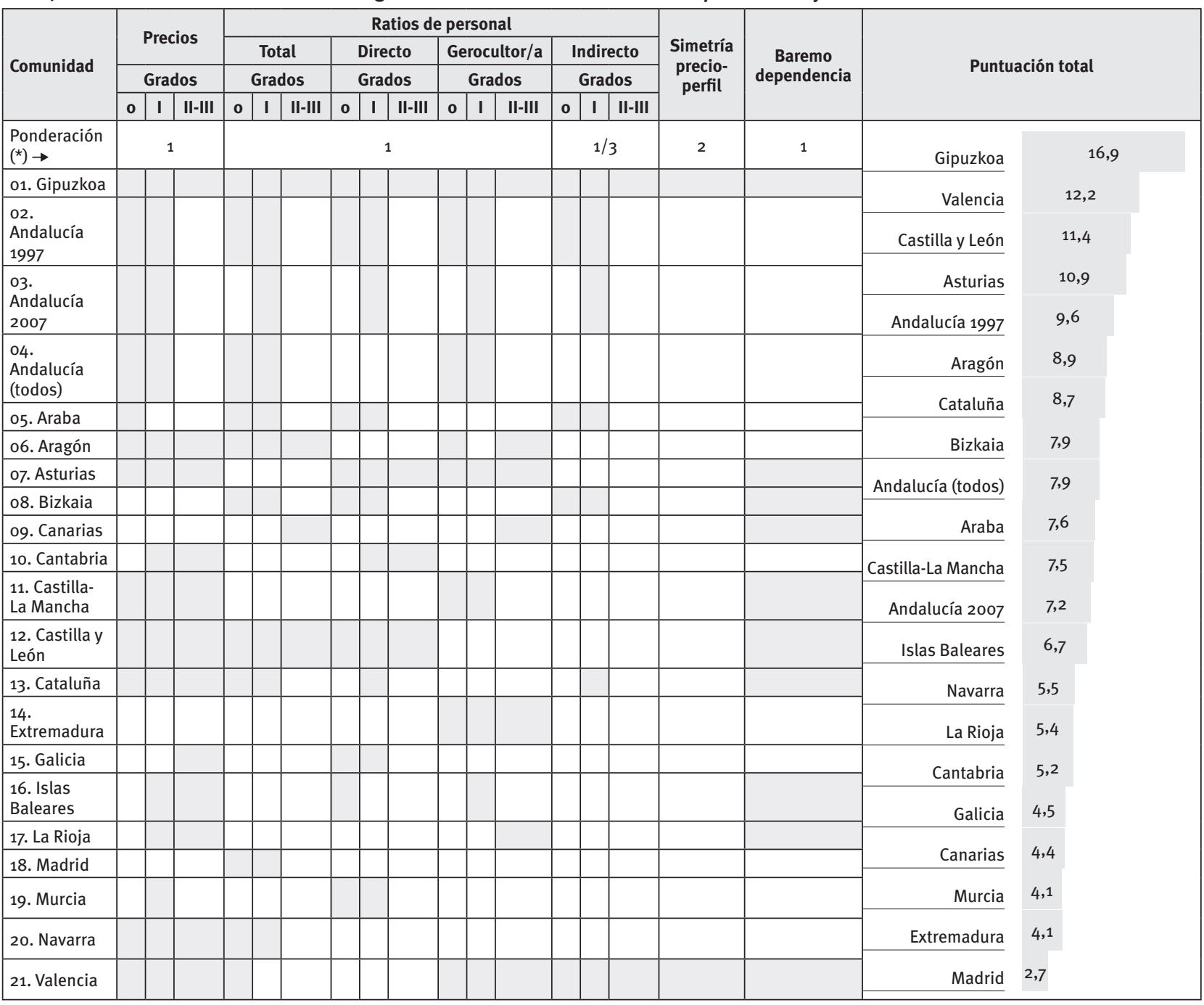

Requisitos materiales (ponderación ${ }^{(* *} \rightarrow 2 / 3$ )

\begin{tabular}{|c|c|c|c|c|c|c|c|c|c|c|c|c|c|c|c|c|c|}
\hline \multirow{2}{*}{ Zona } & \multicolumn{17}{|c|}{ Código de comunidad } \\
\hline & $01-02-06$ & $03-04-05$ & 07 & 08 & 09 & 10 & 11 & 12 & 13 & 14 & 15 & 16 & 17 & 18 & 19 & 20 & 21 \\
\hline \multicolumn{18}{|l|}{ Servicios generales } \\
\hline \multicolumn{18}{|l|}{ Ascensor } \\
\hline \multicolumn{18}{|l|}{ Cocina } \\
\hline \multicolumn{18}{|l|}{ Comedor } \\
\hline \multicolumn{18}{|l|}{ Salones } \\
\hline \multicolumn{18}{|l|}{ Aseo-WC } \\
\hline \multicolumn{18}{|l|}{ Otros } \\
\hline \multicolumn{18}{|l|}{ Atención especializada } \\
\hline \multicolumn{18}{|l|}{ Enfermería } \\
\hline \multicolumn{18}{|l|}{ Rehabilitación } \\
\hline \multicolumn{17}{|l|}{ Terapia ocupacional } & \\
\hline \multicolumn{18}{|l|}{ Residencial } \\
\hline \multicolumn{18}{|l|}{ Tipo de habitación } \\
\hline \multicolumn{18}{|l|}{ Superficie de habitación } \\
\hline \multicolumn{18}{|l|}{ NN.. cuartos de baño } \\
\hline Superficie cuarto de baño & & & & & & & & & & & & & & & & & \\
\hline
\end{tabular}

${ }^{*}$ ( ) La definición de precios, ratios y baremo de dependencia se ponderan a valor 1 porque determinan las características esenciales del servicio; las ratios indirectas a $1 / 3$ porque no son consecuencia de factores intrínsecamente relacionados con la prestación de asistencia y, finalmente, a valor 2 la simetría precioratio porque determina indefectiblemente el volumen de facturación.

(**) Ponderación a valor $2 / 3$ porque, sin restarles importancia, no condicionan la atención al residente en idéntica medida a las ratios y, además, configuran una colección de ítems tan extensa que debemos "amortiguar" su efecto.

Fuente: Elaboración propia/Informe sobre cooperación publico privada en el ámbito de las personas mayores y dependientes (Lares Federación). 


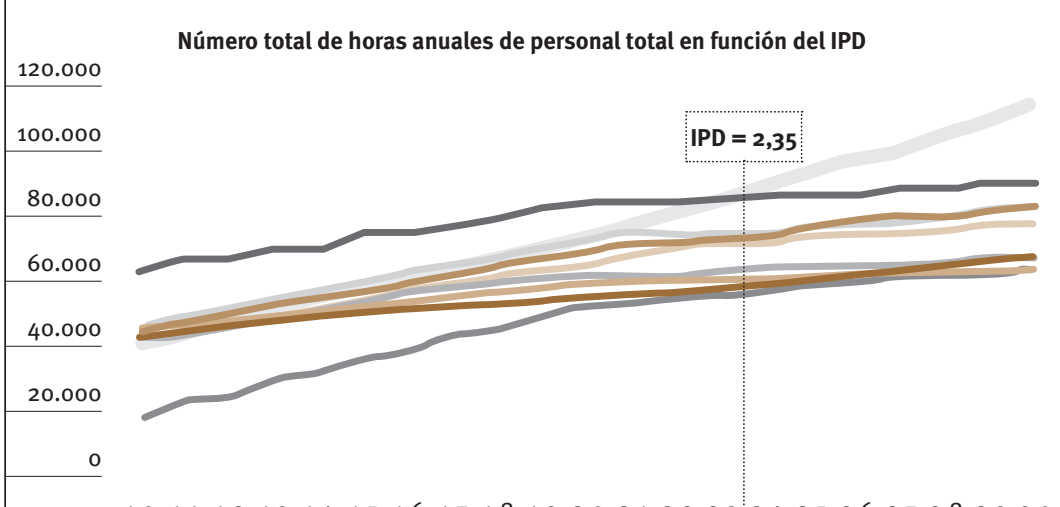

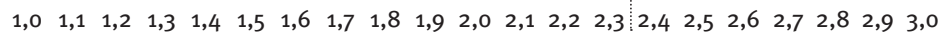

- Respecto de aquellas normativas con ratio total para, al menos, grados o y l, Gipuzkoa propone mayor número de horas de servicio que el resto de comunidades para todo el intervalo [1-3] del IPD, a excepción de Andalucía 1997 y Andalucía 2007 para valores inferiores a 2,35.

- Dicho valor es aquel IPD que iguala ambas ecuaciones polinómicas de regresión. En las actuales circunstancias de atención es bastante probable que la configuración media de un geriátrico esté por encima. En consecuencia, el modelo guipuzcoano normalmente procura mayores plantillas de personal para cualquier IPD real.
Promedio de Gipuzkoa

Promedio de Araba

Promedio de Cataluña

Promedio de Navarra

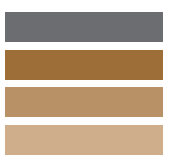

Promedio de Andalucía 1997

Promedio de Aragón

Promedio de Castilla y León

Promedio de Andalucía (todos)
Promedio de Bizkaia

Promedio de Madrid

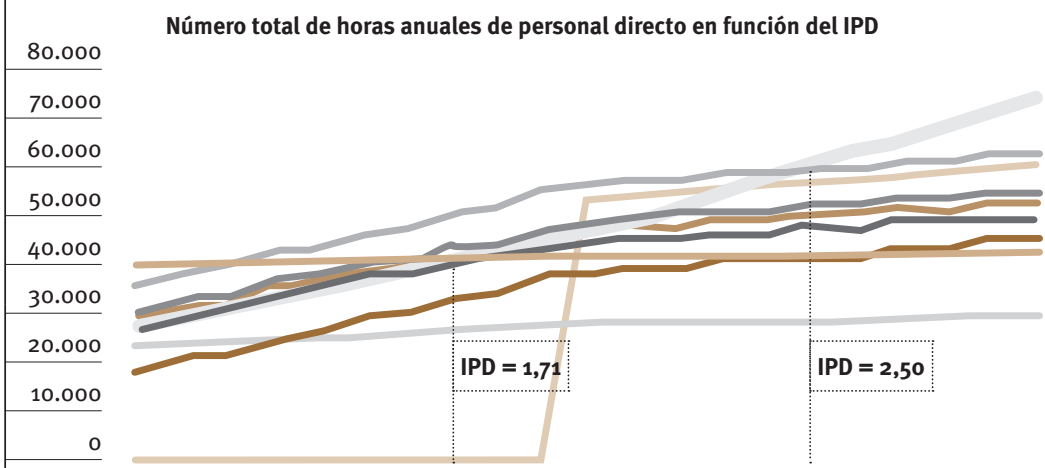

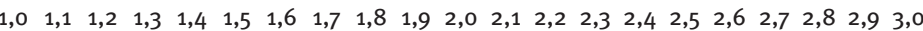

- Escenario análogo al anterior: Gipuzkoa aventaja al resto cuando predomina la concentración de residentes con grados II y III, acrecentando la diferencia a medida que nos trasladamos hacia la derecha en el eje de la dependencia.

- En la comparativa directa con Castilla y León, solo cuando prevalece el porcentaje de residentes autónomos, Gipuzkoa ofrece resultados inferiores. Destaca la escasa influencia del IPD en las horas anuales de Castilla y León.

- Galicia plantea ratios superiores para los grados o y I que no se compensan desde las ratios de Gipuzkoa para grados II y III hasta que el IPD alcanza 2,50 puntos.
Promedio de Gipuzkoa

Promedio de Asturias

Promedio de Galicia

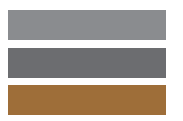

Promedio de Andalucía 1997

Promedio de Bizkaia

Promedio de Murcia
Promedio de Araba

Promedio de Castilla y León

Promedio de Cantabria

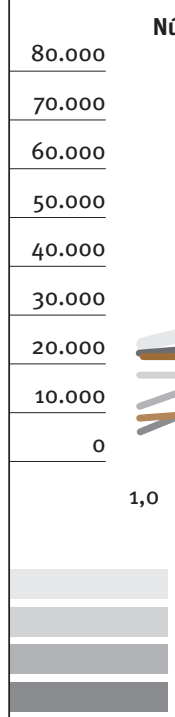

Número total de horas anuales de personal gerocultor en función del IPD

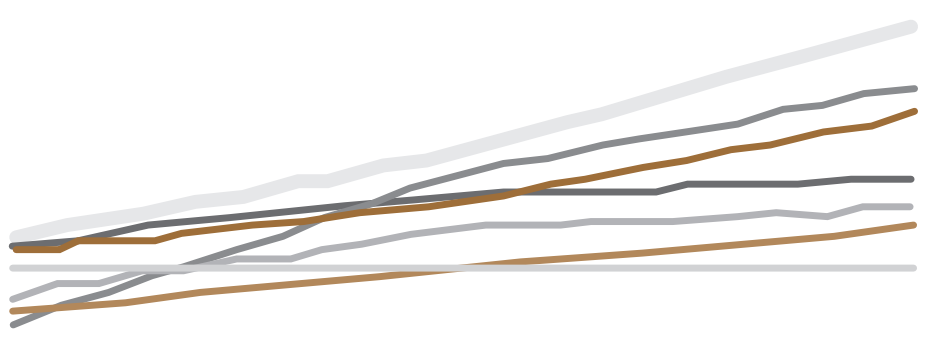

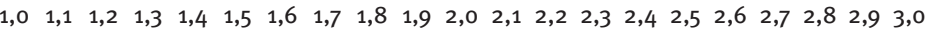

Promedio de Gipuzkoa

Promedio de Andalucía (todos)

Promedio de Castilla-La Mancha

Promedio de Valencia
Promedio de Andalucía 1997

Promedio de Asturias

Promedio de Extremadura
- Gipuzkoa propone la mayor cantidad de horas anuales de gerocultor/a cualquiera que sea el valor de IPD.

- Exclusivamente Asturias y Gipuzkoa reconocen pendientes progresivas (se presume que la necesidad de gerocultor/a aumenta más que proporcionalmente a medida que incrementa la dependencia).

- Únicamente Andalucía 2007 no es sensible a la composición mix de la dependencia (ratio fija de $0,10)$.

- Asturias, Extremadura y Valencia, comunidades que también distinguen tres grupos de dependencia, obtienen resultados dispares: Asturias y Extremadura se alejan de Gipuzkoa a medida que incrementa IPD; Valencia minimiza su diferencia para $I P D=2,15$.

$\left.{ }^{\star}\right)$ Las ecuación de las líneas de regresión se corresponden con aquellas que contienen coeficientes de correlación máximos (de acuerdo con el valor de la correlación, podrían ser cuadráticas o lineales).

Fuente: Elaboración propia. 
Figura 5. Horas anuales de personal para un centro de 100 plazas e IPD $\geq 2,5$

Según ratios totales

90.679

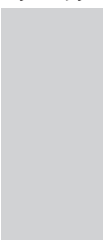

Gipuzkoa

Andalucía

$64 \cdot 772$

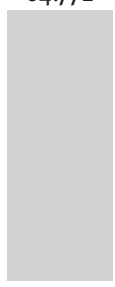

Gipuzkoa 1997
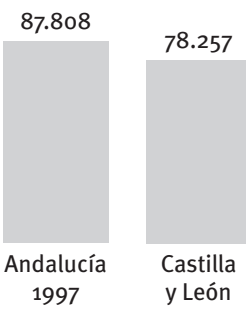

60.384

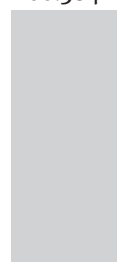

Galicia
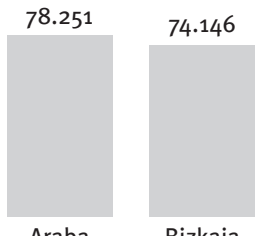

Bizkaia

Araba Bizkaia
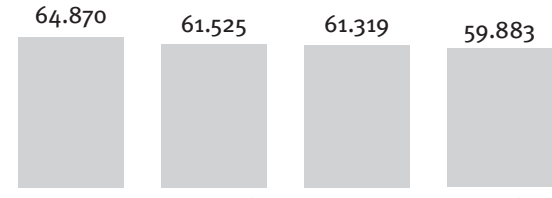

Andalucía Madrid Aragón (todos)
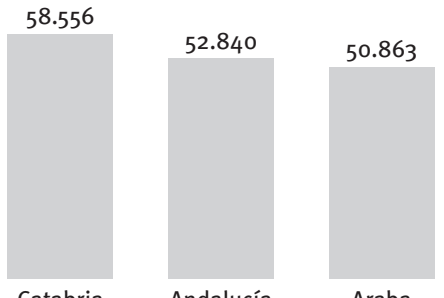

Araba 1997

Según ratios de gerocultor/a
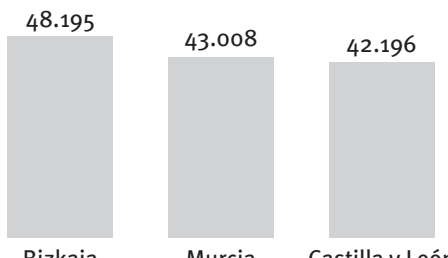

28.648 49.223
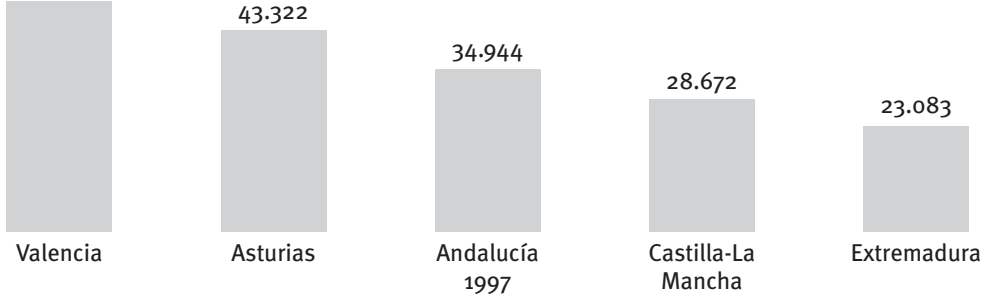

17.920

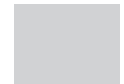

Andalucía (todos)

Fuente: Elaboración propia.

\section{Precios y ratios: análisis descriptivo}

- Gipuzkoa es la comunidad que mayor preocupación muestra por especificar la composición de las plantillas de atención directa y su correspondencia con los grados de dependencia.

- Las diferentes normativas autonómicas sobre precios y ratios proyectan un panorama sensiblemente alejado de la homogeneidad que, sin embargo, tienden en su conjunto a una cierta proporcionalidad en la relación precio-ratio por el efecto que produce dicho par para los grados II y III en Gipuzkoa. Esta supuesta correlación es especialmente acusada para determinadas autonomías (Andalucía, Aragón, Cataluña, Cantabria, Navarra y Valencia).
A medida que incrementa el valor de IPD, Gipuzkoa aumenta las horas de atención en mayor proporción que el resto de comunidades.

\section{Estructuras teóricas del coste de atención}

El diseño de un modelo teórico de costes que facilite la comparativa entre normativas está sujeto a una serie de restricciones que dificultan y limitan el estudio y que, en consecuencia, exigen ampararnos en ciertas hipótesis para ordenar los criterios de comparación. Entre las referidas restricciones destacamos:

- Escasez de estudios sobre la composición del coste plaza (según cita Díaz Díaz, las últimas experiencias han sido: Centro Europeo de Empresas e Innovación de Navarra, 2003; Montserrat, 2005; Deloitte, 2006; Guillén, 2007; BIC Galicia, 2008 y Deloitte, 2008).

- Indefinición de la composición modular del precio y coste por plaza por parte de las Administraciones Públicas (falta de transparencia en el cálculo del coste por plaza).

- Desconocimiento de la distribución de costes (lo que Guadalajara Olmedo -1996-, identifica como costes fijos, semifijos, variables y 
semivariables) y de las sinergias producidas por las economías de escala.

- Tratamiento y efecto del IVA.

- Adecuación de los costes de amortización de los inmuebles al coste de construcción de cada autonomía (valor tasado medio de vivienda según el Ministerio de Fomento).

En un sector tan disgregado como el analizado, la posibilidad de comparación intercomunitaria pasa ineludiblemente por reconocer una variable que represente todas las posibles casuísticas de atención (composición del índice case-mix, tamaño residencial, distribución del personal, gastos de funcionamiento y amortización, entre otros). La única opción posible y viable para homogeneizar la paridad entre normativas es la cuantificación de un coste por residente y día. A su vez, esta variable no indivisa estaría conformada por los siguientes sumandos: coste de personal derivado de las ratios de atención $\left(r_{t} y \mathrm{CH}\right)$, costes de amortización adaptados $(A)$ y gastos de funcionamiento estandarizados y contextualizados en cada autonomía en función del índice de coste de la vida (GF). En definitiva, realizaremos un ejercicio teórico para componer un coste unitario de correlación desconocida con una realidad asistencial que, muy probablemente, haya evolucionado en un plano alternativo al propuesto por las diferentes normativas autonómicas. Nuestro objetivo no es describir un modelo de cálculo de costes residenciales, sino simular la potencia de cada autonomía para conseguir determinados márgenes de beneficio con un cumplimiento escrupuloso de sus respectivas normativas; 0 , lo que es lo mismo, expresar una función de precio, $\mathrm{P}=\mathrm{f}\left(\mathrm{r}_{t}, \mathrm{CH}, \mathrm{GF}, \mathrm{A}, \mathrm{MB}\right)$, que admita comparativas intercomunitarias para un margen de beneficio a priori (MB). El estudio no trata de reflejar una realidad que comúnmente presenta costes reales de atención por encima de los precios públicos ("el coste medio diario por usuario es de 56,48 euros, claramente superior a la financiación pública recibida", extracto del estudio encargado por Lares Valencia y publicado bajo el título Evaluación de costes y financiación de las residencias de mayores. El sector no lucrativo en la Comunidad Valenciana) sino de comprobar cómo las normativas públicas tratan de manera desigual la relación entre precios y costes teóricos.

Respecto a la incidencia del IVA en el precio y su repercusión en el margen de beneficio podrían distinguirse diferentes situaciones. En la práctica, coexisten organizaciones ganadoras de un proceso de licitación pública que desarrollan su actividad en inmuebles de titularidad pública con o sin ánimo de lucro, instituciones propietarias sin endeudamiento para adquisición de edificios y entidades que prestan servicios en centros de nueva construcción con financiación ajena. En todos los casos, la forma jurídica del prestador de servicios determinará la exención o no en la declaración del IVA para plazas concertadas. Que un precio resulte más rentable con o sin IVA dependerá fundamentalmente, entre otras razones, del volumen de inversión y de la cantidad facturada por las subcontratas de personal, si es el caso. Para ordenar y homogeneizar nuestro análisis, partiremos de los siguientes presupuestos: precios de referencia no sujetos a IVA, plantillas propias de personal y niveles de financiación estándar para la adquisición o rehabilitación de inmuebles.

\subsection{Costes de personal}

El coste de personal para cada grado de dependencia es una función que dependerá de variables como la ratio, la jornada anual, el coste/hora y la distribución de personal equivalente por categorías profesionales (lo que más adelante catalogamos como "escenarios"). El coste/hora es una derivada directa de los respectivos convenios colectivos de aplicación que, en el conjunto del Estado, están mayoritariamente representados por el Convenio colectivo marco estatal de servicios de atención a las personas dependientes y desarrollo de la promoción de la autonomía personal.

Tabla 5. Jornadas y coste por hora según los diferentes convenios colectivos de aplicación

\begin{tabular}{|l|c|c|}
\hline Comunidad & $\begin{array}{c}\text { Jornada } \\
\left(\mathbf{J}_{\mathrm{j}}\right)\end{array}$ & $\begin{array}{c}\text { Coste } \\
\text { hora } \\
\left(\mathrm{CH}_{\mathrm{k}}\right)\end{array}$ \\
\hline Gipuzkoa & 1.592 & 13,042 \\
\hline Bizkaia & 1.683 & 11,091 \\
\hline $\begin{array}{l}\text { Promedio } \\
\text { del resto de } \\
\text { comunidades }\end{array}$ & 1.789 & 7,652 \\
— desviación: $0,149(1,94 \%)$ \\
\hline
\end{tabular}

Fuente: Convenioscolectivos.net y CIS26o Laboral.

En general, tras analizar las normativas laborales vigentes, verificamos los siguientes hechos:

- Salvo en Gipuzkoa y Bizkaia, la jornada anual se mueve entre un mínimo de 1.776 horas y un máximo de 1.792, para una media de 1.789 horas con un desviación de apenas un 0,3\%.

- Los salarios son netamente superiores en ambos territorios a los del resto de comunidades, que mantienen una retribución prácticamente igual a la establecida por el convenio estatal, a excepción de la Comunidad Valenciana para residencias de tercera edad con contrato público.

- Casi tres cuartas partes de las comunidades autónomas se adhieren, a todos los efectos, al convenio colectivo de marco estatal. Para el resto de comunidades - excepto Gipuzkoa y Bizkaialas diferencias respecto al convenio estatal son prácticamente marginales.

Si denotamos como $\mathrm{CP}_{i}$ el coste de personal para un determinado grado de dependencia, 


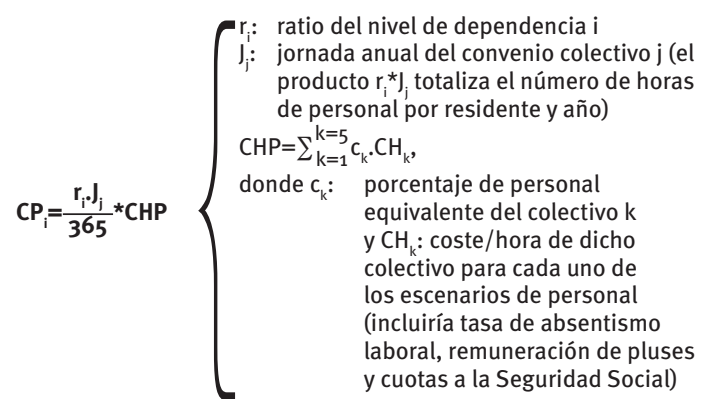

el valor ponderado de dicho coste para cada IPD adoptaría la siguiente expresión:

$$
\begin{aligned}
& \mathrm{CMPP}=\frac{\mathrm{J}_{\mathrm{i}}}{365} * \frac{\sum_{\mathrm{i}=1}^{\mathrm{i}=3} \mathrm{r}_{\mathrm{i}} \cdot \mathrm{n}_{\mathrm{i}}}{\mathrm{n}} * \mathrm{CHP}=\frac{\sum_{\mathrm{i}=1}^{\mathrm{i}=3} \mathrm{CP} \mathrm{P}_{\mathrm{i}} \cdot \mathrm{n}_{\mathrm{i}}}{\mathrm{n}}, \\
& \text { donde } \mathrm{n}_{\mathrm{i}}: \text { número de residentes de grado } \mathrm{i}
\end{aligned}
$$

¿Qué se entiende por escenario de personal? Cada centro residencial organiza sus recursos humanos conforme a su know-how, cumpliendo las disposiciones y normativas aplicables en su caso. No es cometido del presente estudio la valoración cualitativa de los modelos de atención que, en todo caso, desembocan en una supuesta adecuación de recursos a necesidades para cada categoría profesional. No obstante, el dimensionamiento de plantillas no se produce desatendiendo la proporcionalidad entre personal directo e indirecto que debe guiar cualquier diseño asistencial. De hecho, normativas como el Decreto 41/1998 de Euskadi equilibran la presencia de atención indirecta en mínimos del $35 \%$ respecto de la atención total. Dada la obligada participación de ambas categorías para garantizar una prestación de calidad estándar y dada, también, la inalcanzable capacidad de contar con datos estatales fidedignos que correlacionen modelos de atención con índices case-mix, deberemos idear escenarios verosímiles que reflejen coherentemente los estándares de atención residencial integral a las personas mayores. La asignación de profesionales a cada ámbito de actuación debería ser armoniosa y no sería aconsejable que reprodujera escenarios descompensados que sesgaran intencionadamente los resultados de nuestro proyecto. La relación directaindirecta fluctuará en la horquilla $\left[\frac{0,75}{0,25}, 0,0,45\right]$ y la configuración de cada estrato profesional será tal que pueda ser contrastada empíricamente.

Tabla 6. Definición de escenarios de personal equivalente

\begin{tabular}{|l|l|}
\hline Nivel 1: tipo de atención (alternativa 1) & $55 \%$ \\
\hline At. Directa $\left(r_{d}\right)$ & $45 \%$ \\
\hline At. Indirecta $\left(r_{i}\right)$ & \\
\hline
\end{tabular}

\begin{tabular}{|l|c|c|c|}
\hline Nivel 2: reparto de atención directa & $70 \%$ & $80 \%$ & $90 \%$ \\
\hline Básico: gerocultor/a y DUE $\left(\mathrm{r}_{\mathrm{db}}\right)$ & $30 \%$ & $20 \%$ & $10 \%$ \\
\hline Resto $\left(\mathrm{r}_{\mathrm{dr}}\right)$ & & \multicolumn{3}{|l|}{} \\
\hline
\end{tabular}

\begin{tabular}{|c|c|c|c|c|}
\hline \multirow{2}{*}{\multicolumn{2}{|c|}{ Gerucultor $\left(r_{\mathrm{dbp}}\right)$}} & & & \\
\hline & & $70 \%$ & $80 \%$ & $90 \%$ \\
\hline \multicolumn{2}{|c|}{$\operatorname{DUE}\left(r_{\mathrm{dbe}}\right)$} & $30 \%$ & $20 \%$ & $10 \%$ \\
\hline \multirow{2}{*}{ At. indirecta: } & Titulado/a universitario/a $\left(\mathrm{r}_{\mathrm{it}}\right)$ & $30 \%$ & $20 \%$ & $10 \%$ \\
\hline & Resto $\left(r_{i}\right)$ & $70 \%$ & $80 \%$ & $90 \%$ \\
\hline
\end{tabular}

Nivel 3: reparto por colectivos

\begin{tabular}{|c|c|c|c|c|c|c|c|c|c|c|}
\hline \multicolumn{2}{|c|}{ Escenarios (alternativa $1\left(^{(}\right)$) } & 1.1.1 & 1.1.2 & 1.1.3 & 1.2.1 & 1.2.2 & 1.2 .3 & 1.3.1 & 1.3.2 & 1.3 .3 \\
\hline \multirow{3}{*}{ Directa: } & Gerocultor/a $\mathrm{a}^{(1)}$ & $27 \%$ & $31 \%$ & $35 \%$ & $31 \%$ & $35 \%$ & $40 \%$ & $35 \%$ & $40 \%$ & $45 \%$ \\
\hline & DUE $\left.^{(2)}\right)$ & $12 \%$ & $8 \%$ & $4 \%$ & $13 \%$ & $9 \%$ & $4 \%$ & $15 \%$ & $10 \%$ & $5 \%$ \\
\hline & Resto(3) & $17 \%$ & $17 \%$ & $17 \%$ & $11 \%$ & $11 \%$ & $11 \%$ & $6 \%$ & $6 \%$ & $6 \%$ \\
\hline \multirow{2}{*}{ Indirecta: } & Titulado/a universitario/a $\mathrm{a}^{(4)}$ & $14 \%$ & $9 \%$ & $5 \%$ & $14 \%$ & $9 \%$ & $5 \%$ & $14 \%$ & $9 \%$ & $5 \%$ \\
\hline & Resto $^{(5)}$ & $32 \%$ & $36 \%$ & $41 \%$ & $32 \%$ & $36 \%$ & $41 \%$ & $32 \%$ & $36 \%$ & $41 \%$ \\
\hline
\end{tabular}

\begin{tabular}{|c|c|c|c|c|c|c|c|c|c|c|c|c|}
\hline \multirow{2}{*}{\multicolumn{2}{|c|}{ Escenarios (alternativa 2) }} & At. directa & $65 \%$ & \multirow{2}{*}{1.1 .1} & \multirow{2}{*}{ 1.1.2 } & \multirow{2}{*}{ 1.1.3 } & \multirow{2}{*}{1.2 .1} & \multirow{2}{*}{1.2 .2} & \multirow{2}{*}{1.2 .3} & \multirow{2}{*}{ 1.3.1 } & \multirow{2}{*}{1.3 .2} & \multirow{2}{*}{1.3 .3} \\
\hline & & At. Indirecta & $35 \%$ & & & & & & & & & \\
\hline \multirow{3}{*}{ Directa: } & \multicolumn{3}{|c|}{ Gerocultor/a } & $32 \%$ & $36 \%$ & $41 \%$ & $36 \%$ & $42 \%$ & $47 \%$ & $41 \%$ & $47 \%$ & $53 \%$ \\
\hline & \multicolumn{3}{|c|}{ DUE } & $14 \%$ & $9 \%$ & $5 \%$ & $16 \%$ & $10 \%$ & $5 \%$ & $18 \%$ & $12 \%$ & $6 \%$ \\
\hline & \multicolumn{3}{|l|}{ Resto } & $20 \%$ & $20 \%$ & $20 \%$ & $13 \%$ & $13 \%$ & $13 \%$ & $7 \%$ & $7 \%$ & $7 \%$ \\
\hline \multirow{2}{*}{ Indirecta: } & \multicolumn{3}{|c|}{ Titulado/a universitario/a } & $11 \%$ & $7 \%$ & $4 \%$ & $11 \%$ & $7 \%$ & $4 \%$ & $11 \%$ & $7 \%$ & $4 \%$ \\
\hline & \multicolumn{3}{|c|}{ Resto } & $25 \%$ & $28 \%$ & $32 \%$ & $25 \%$ & $28 \%$ & $32 \%$ & $25 \%$ & $28 \%$ & $32 \%$ \\
\hline
\end{tabular}

\begin{tabular}{|c|c|c|c|c|c|c|c|c|c|c|c|c|}
\hline \multirow{2}{*}{\multicolumn{2}{|c|}{ Escenarios (alternativa 3) }} & At. directa & $75 \%$ & \multirow{2}{*}{ 1.1.1 } & \multirow{2}{*}{ 1.1.2 } & \multirow{2}{*}{1.1 .3} & \multirow{2}{*}{ 1.2.1 } & \multirow{2}{*}{1.2 .2} & \multirow{2}{*}{1.2 .3} & \multirow{2}{*}{1.3 .1} & \multirow{2}{*}{1.3 .2} & \multirow{2}{*}{1.3 .3} \\
\hline & & At. Indirecta & $25 \%$ & & & & & & & & & \\
\hline \multirow{3}{*}{ Directa: } & \multicolumn{3}{|l|}{ Gerocultor/a } & $37 \%$ & $42 \%$ & $47 \%$ & $42 \%$ & $48 \%$ & $54 \%$ & $47 \%$ & $54 \%$ & $61 \%$ \\
\hline & \multicolumn{3}{|l|}{ DUE } & $16 \%$ & $11 \%$ & $5 \%$ & $18 \%$ & $12 \%$ & $6 \%$ & $20 \%$ & $14 \%$ & $7 \%$ \\
\hline & \multicolumn{3}{|c|}{ Resto } & $23 \%$ & $23 \%$ & $23 \%$ & $15 \%$ & $15 \%$ & $15 \%$ & $8 \%$ & $8 \%$ & $8 \%$ \\
\hline \multirow{2}{*}{ Indirecta: } & \multicolumn{3}{|c|}{ Titulado/a universitario/a } & $8 \%$ & $5 \%$ & $3 \%$ & $8 \%$ & $5 \%$ & $3 \%$ & $8 \%$ & $5 \%$ & $3 \%$ \\
\hline & \multicolumn{3}{|l|}{ Resto } & $18 \%$ & $20 \%$ & $23 \%$ & $18 \%$ & $20 \%$ & $23 \%$ & $18 \%$ & $20 \%$ & $23 \%$ \\
\hline
\end{tabular}

Cálculo del peso específico de cada colectivo: (1) Gerocultor: $r_{d} \bullet r_{d b} \bullet r_{d b g} /$ (2) DUE: $r_{d} \bullet r_{d b} \bullet r_{d b r} /$ (3) Resto at. directa: $r_{d} \bullet r_{d r}$ (4) Titulado/a at. indirecta: $r_{i} \bullet r_{i t} /(5)$ Resto at. indirecta: $r_{i} \bullet r_{i r}$ 
Tan solo la acción combinada entre ratio total y nivel de dependencia podría asignar la proporción teórica entre precio y coste de personal. Sin embargo, no todas las normativas determinan ratios totales. Esta limitación sugiere la estimación de dicha proporción desde ratios de atención directa e, incluso, desde ratios de gerocultor/a, de acuerdo con los repartos de personal equivalente de cada escenario y siempre que los estimadores ofrezcan resultados coherentes (recordemos que el personal equivalente es el número de personas a jornada completa o cociente entre el total de horas de personal de plantilla y jornada anual de referencia).

Se han desplegado un total de 27 escenarios que probablemente darían suficiente contenido asistencial a todo el recorrido del IPD. La realidad asistencial extendida por todas las autonomías sugiere que son más verosímiles valores superiores a 2,3-2,4 puntos, lo que denota una mayor exigencia de personal directo que se traduce en un progresivo incremento de la variable $c_{k}$ para las categorías profesionales de gerocultor/a, DUE y personal no cualificado de atención indirecta. Los pesos relativos de las referidas categorías aumentan en detrimento de otras figuras profesionales y los escenarios 1.3.3., 2.3.3. y 3.3.3. se manifiestan como especialmente oportunos. En concreto, el 2.3.3. cumple con dos relaciones intrínsecas al modelo de Gipuzkoa: ratio entre atención directa e indirecta de 1,86 (0,65/0,35, como prevé el Decreto 41/1998 del Gobierno Vasco, norma que exclusivamente regula esta relación) y proporción aproximada de DUE sobre gerocultores/as del $10 \%(0,06 / 0,53=0,11)$.
Calculemos la expresión de $\mathrm{CP}_{\mathrm{i}}$ para ratios totales reales o adecuémosla a las ratios de atención directa (Asturias, Galicia y Murcia) y a las ratios de gerocultor/a (Castilla-La Mancha, Islas Baleares, La Rioja y Valencia) previstas en el escenario 2.3.3. Se aprecia un mismo efecto medio para el conjunto de normativas con binomios precio-ratio: a medida que crece la dependencia, también lo hace el porcentaje teórico del coste de personal sobre el precio correspondiente a cada categoría de ratio (lectura vertical de la Tabla 9). Se trata de una consecuencia previsible si el diferencial del insumo "mano de obra" es sensiblemente mayor - por su efecto multiplicador- que en otros inputs de consumo variable, netamente vinculados a las necesidades específicas de perfiles de atención cada vez más exigentes. Sin embargo, esta premisa no se cumple por igual en todos los casos: $65 \%$ para ratios totales, $83 \%$ para ratios de atención directa y $71 \%$ para ratios de gerocultor/a, con valor promedio total del $74 \%$ (lectura horizontal de la Tabla 9). Podríamos interpretar -como probable razón que justifique el incumplimiento- que el precio público no reacciona en suficiente medida a los incrementos de ratios por paso a estadios superiores de dependencia.

El porcentaje del coste teórico de personal es el cociente entre el coste medio ponderado de personal (CMPP) y el precio ponderado de referencia (P). Siempre referidas a unidades medidas por plaza y día, ambas variables están condicionadas por la distribución del centro por grados de dependencia $\left(n_{i}\right)$ que, a su vez, determinan el IPD. Buscar una relación matemática exacta entre ambas variables,

Tabla 7. Ratios de referencia para estimación de costes de personal para cada nivel de dependencia

\begin{tabular}{|l|c|c|c|}
\hline Normativa & Grado o & Grado I & Grados II-III \\
\hline Gipuzkoa & Total & Total & Total \\
\hline Andalucía 1997 & Total & Total & \\
\hline Andalucía 2007 & & Total & \\
\hline Andalucía (todos) & Total & Total & \\
\hline Araba & Total & Total & \\
\hline Aragón & Total & Total & Total \\
\hline Asturias & Directa & Directa & Gerocultor/a \\
\hline Bizkaia & Total & Total & \\
\hline Canarias (*) & & & \\
\hline Cantabria & & Directa & Directa \\
\hline Castilla - La Mancha & Gerocultor/a & Gerocultor/a & \\
\hline
\end{tabular}

\begin{tabular}{|l|c|c|c|}
\hline Normativa & Grado o & Grado I & Grados II-III \\
\hline Castilla y León & Total & Total & Total \\
\hline Cataluña & Total & Total & \\
\hline Extremadura & Gerocultor/a & Gerocultor/a & Gerocultor/a \\
\hline Galicia & Directa $(* \star)$ & Directa & \\
\hline Islas Baleares & & Gerocultor/a & \\
\hline La Rioja & & & Gerocultor/a \\
\hline Madrid & Total & Total & \\
\hline Murcia & Directa & Directa & \\
\hline Navarra & Total & Total & \\
\hline Valencia & Gerocultor/a & Gerocultor/a & Gerocultor/a \\
\hline
\end{tabular}

(*) Sin precio y sin ratios grados o o l / (**) Sin precio pero con ratio

\begin{tabular}{|c|c|c|}
\hline \multirow{2}{*}{ - Normativas sin precio } & CPi estimado desde ratio totales (al menos grados o y I): & 1 \\
\hline & CPi estimado desde ratio de gerocultor/a (al menos grados o y l): & 1 \\
\hline \multirow{2}{*}{$\begin{array}{l}\text { - Normativas con precio y CPi calculado conforme a ratios totales } \\
\text { reales }\end{array}$} & Al menos de grados o y l: & 9 \\
\hline & Al menos de grado I: & 1 \\
\hline \multirow{2}{*}{$\begin{array}{l}\text { - Normativas con precio y CPi calculado conforme a ratios totales } \\
\text { estimados desde ratios de atención directa }\end{array}$} & Al menos de grados o y l: & 3 \\
\hline & Al menos de grado I: & 1 \\
\hline \multirow{3}{*}{$\begin{array}{l}\text { - Normativas con precio y CPi calculado conforme a ratios totales } \\
\text { estimados desde ratios de gerocultor/a }\end{array}$} & Al menos de grados o y l: & 1 \\
\hline & Al menos de grado I: & 3 \\
\hline & Total normativas con datos: & 20 \\
\hline
\end{tabular}

Fuente: Elaboración propia. 
enunciada en términos de $n_{i}$, complica excesivamente los cálculos y, dada la altísima correlación entre IPD $\mathrm{y} \% \mathrm{CMPP} / \mathrm{P}$, procede sustituir la relación original por ecuaciones cuadráticas de regresión que simplifiquen el análisis de nuestro proyecto (\%CMPP $\left.=a^{2} \cdot|P D+b \cdot| P D+c\right)$. Como veremos más adelante, el índice ponderado de dependencia es la variable que delimita el punto a partir del cual una normativa proporciona mayores potencialidades que el resto para cumplir con sus respectivas obligaciones $y$, además, obtener un margen de beneficio predeterminado.

Tabla 8. Porcentaje sobre el precio de los costes de personal según el tipo de ratio $\left(^{\star}\right)$

\begin{tabular}{|c|c|c|c|c|c|c|c|c|c|c|c|c|c|c|}
\hline \multirow{3}{*}{ Normativa } & \multicolumn{6}{|c|}{ Totales } & \multirow{3}{*}{ Normativa } & \multirow{2}{*}{\multicolumn{3}{|c|}{$\begin{array}{c}\text { Atención directa } \\
\text { Escenario 2.3.3 }\end{array}$}} & \multirow{3}{*}{ Normativa } & \multirow{2}{*}{\multicolumn{3}{|c|}{ Gerocultor/a }} \\
\hline & \multicolumn{3}{|c|}{ Escenario 2.3.3 } & \multicolumn{3}{|c|}{ Escenario promedio } & & & & & & & & \\
\hline & $\begin{array}{c}\text { Grado } \\
0 \\
\end{array}$ & \begin{tabular}{|c|} 
Grado \\
I
\end{tabular} & $\begin{array}{c}\text { Grados } \\
\text { II-III }\end{array}$ & $\begin{array}{c}\text { Grado } \\
0 \\
\end{array}$ & \begin{tabular}{|c|}
$\begin{array}{c}\text { Grado } \\
\text { I }\end{array}$ \\
\end{tabular} & \begin{tabular}{|c|} 
Grados \\
II-III \\
\end{tabular} & & $\begin{array}{c}\text { Grado } \\
0 \\
\end{array}$ & $\begin{array}{c}\text { Grado } \\
\text { I }\end{array}$ & $\begin{array}{c}\text { Grados } \\
\text { II-III }\end{array}$ & & $\begin{array}{c}\text { Grado } \\
0 \\
\end{array}$ & $\begin{array}{c}\text { Grado } \\
\text { I }\end{array}$ & $\begin{array}{c}\text { Grados } \\
\text { II-III }\end{array}$ \\
\hline Gipuzkoa & $38,1 \%$ & $50,4 \%$ & $67,4 \%$ & $41,0 \%$ & $54,3 \%$ & $72,6 \%$ & Gipuzkoa & $25,4 \%$ & $33,8 \%$ & $45,1 \%$ & Gipuzkoa & $20,2 \%$ & $26,6 \%$ & $37,4 \%$ \\
\hline $\begin{array}{l}\text { Andalucía } \\
1997\end{array}$ & $38,4 \%$ & $46,8 \%$ & & $79,4 \%$ & $61,4 \%$ & & $\begin{array}{l}\text { Andalucía } \\
1997\end{array}$ & $18,6 \%$ & $29,0 \%$ & & Andalucía & $21,9 \%$ & $18,4 \%$ & \\
\hline $\begin{array}{l}\text { Andalucía } \\
2007\end{array}$ & & $46,8 \%$ & & & $61,4 \%$ & & Araba & $22,5 \%$ & $40,6 \%$ & & Aragón & $10,4 \%$ & $22,3 \%$ & $22,3 \%$ \\
\hline $\begin{array}{l}\text { Andalucía } \\
\text { (todos) }\end{array}$ & $27,4 \%$ & $32,8 \%$ & & $56,7 \%$ & $43,0 \%$ & & Asturias & $18,1 \%$ & $22,6 \%$ & $40,2 \%$ & Asturias & $15,6 \%$ & $19,5 \%$ & $32,8 \%$ \\
\hline Araba & $34,1 \%$ & $61,4 \%$ & & $36,0 \%$ & $64,9 \%$ & & Bizkaia & $16,6 \%$ & $29,9 \%$ & & $\begin{array}{l}\text { Castilla-La } \\
\text { Mancha }\end{array}$ & $11,0 \%$ & $21,6 \%$ & $18,9 \%$ \\
\hline Aragón & $55,2 \%$ & $35,4 \%$ & $41,3 \%$ & $58,3 \%$ & $37,4 \%$ & $43,6 \%$ & Cantabria & & $39,6 \%$ & $37,4 \%$ & Valencia & $4,6 \%$ & $27,5 \%$ & $31,2 \%$ \\
\hline Bizkaia & $26,6 \%$ & $47,8 \%$ & & $26,4 \%$ & $47,5 \%$ & & $\begin{array}{l}\text { Castilla y } \\
\text { León }\end{array}$ & $41,7 \%$ & $32,2 \%$ & $34,7 \%$ & Promedio & $14,0 \%$ & $22,7 \%$ & $28,5 \%$ \\
\hline $\begin{array}{l}\text { Castilla y } \\
\text { León }\end{array}$ & $46,5 \%$ & $54,9 \%$ & $53,9 \%$ & $49,1 \%$ & $58,0 \%$ & $56,9 \%$ & Promedio & $23,8 \%$ & $32,5 \%$ & $39,3 \%$ & & & & \\
\hline Cataluña & $51,7 \%$ & $40,6 \%$ & $34,6 \%$ & $54,6 \%$ & $42,9 \%$ & $36,6 \%$ & & & & & & & & \\
\hline Navarra & $23,1 \%$ & $44,0 \%$ & $41,9 \%$ & $24,4 \%$ & $46,5 \%$ & $44,3 \%$ & & & & & & & & \\
\hline Promedio & $37,9 \%$ & $46,1 \%$ & $47,8 \%$ & $47,3 \%$ & $51,7 \%$ & $50,8 \%$ & & & & & & & & \\
\hline
\end{tabular}

(*) Como se observa, la normativa de Gipuzkoa para el escenario seleccionado es la que descubre una mayor proporción de los costes de personal sobre el precio para los grados II y III (72,6\% para el escenario medio). Para grados o y I se sitúa por encima de la media pero no destaca especialmente. Vuelve a corroborarse la idea de que Gipuzkoa se desmarca del resto de normativas por el tratamiento específico de los grados II y III.

Fuente: Elaboración propia.

Tabla 9. Evolución del porcentaje de costes teóricos de personal (\% CMPP(*)) sobre el precio (P) en función del IPD

\begin{tabular}{|c|c|c|c|c|c|c|c|c|c|c|c|c|}
\hline \multirow{2}{*}{\multicolumn{4}{|c|}{$\begin{array}{r}\text { Correlación polinómica } \rightarrow \\
\text { Composición del mix }\end{array}$}} & 0,9997 & 0,9976 & 0,9900 & \multirow{2}{*}{\multicolumn{2}{|c|}{\begin{tabular}{l|l|}
0,9958 & 0,9976 \\
Normativas
\end{tabular}}} & 0,9900 & 0,9964 & 0,9982 & \multirow[t]{2}{*}{0,9946} \\
\hline & & & & & & & & & & & & \\
\hline G-o & G-I & G-II/III & IPD (4) & Gipuzkoa & Bizkaia & Andalucía 1997 & Andalucía (todos) & Araba & Aragón & Castilla y León & Cataluña & Navarra \\
\hline 100 & 0 & 0 & 1,0 & $38,1 \%$ & $25,2 \%$ & $75,1 \%$ & $53,6 \%$ & $34,1 \%$ & $55,2 \%$ & $46,5 \%$ & $51,7 \%$ & $23,1 \%$ \\
\hline 90 & 0 & 10 & 1,2 & $42,3 \%$ & $27,2 \%$ & $72,2 \%$ & $51,4 \%$ & $36,8 \%$ & $52,8 \%$ & $47,6 \%$ & $48,3 \%$ & $26,4 \%$ \\
\hline 90 & 10 & 0 & 1,1 & $39,5 \%$ & $27,2 \%$ & $72,2 \%$ & $51,4 \%$ & $36,8 \%$ & $51,8 \%$ & $47,6 \%$ & $49,7 \%$ & $26,6 \%$ \\
\hline 40 & 60 & 0 & 1,6 & $46,1 \%$ & $37,3 \%$ & $62,6 \%$ & $44,1 \%$ & $50,5 \%$ & $40,6 \%$ & $52,2 \%$ & $43,5 \%$ & $38,4 \%$ \\
\hline 30 & 0 & 70 & 2,4 & $60,9 \%$ & $39,3 \%$ & $61,2 \%$ & $43,1 \%$ & $53,2 \%$ & $43,9 \%$ & $52,3 \%$ & $37,4 \%$ & $38,5 \%$ \\
\hline 0 & 80 & 20 & 2,2 & $54,5 \%$ & $45,3 \%$ & $58,0 \%$ & $40,6 \%$ & $61,4 \%$ & $36,5 \%$ & $54,6 \%$ & $39,2 \%$ & $43,6 \%$ \\
\hline 0 & 90 & 10 & 2,1 & $52,5 \%$ & $45,3 \%$ & $58,0 \%$ & $40,6 \%$ & $61,4 \%$ & $36,0 \%$ & $54,8 \%$ & $39,9 \%$ & $43,8 \%$ \\
\hline 0 & 100 & 0 & 2,0 & $50,4 \%$ & $45,3 \%$ & $58,0 \%$ & $40,6 \%$ & $61,4 \%$ & $35,4 \%$ & $54,9 \%$ & $40,6 \%$ & $44,0 \%$ \\
\hline$\frac{80}{70} \frac{0}{60}$ & & Porcentaj & je de $\cos t$ & tes totales $\mathrm{t}$ & teóricos de & le personal sobre & precios en función d & l índice $p$ & onderado & de dependencia & (IPD) & \\
\hline 50 & & & & & & & & & & & & \\
\hline$\frac{40}{30}$ & & & & & & & & & & & & \\
\hline 20 & & & & & & & & & & & & \\
\hline 10 & & & & & & & & & & & & \\
\hline & & & & & & & & & & & & \\
\hline & 1,0 & 1,1 & 1,2 & 1,4 & 1,6 & 1,8 & 2,0 & 2,3 & 2,4 & 2,6 & 2,8 & 3,0 \\
\hline & & Prome & dio de G & ipuzkoa & & Prom & nedio de Bizkaia & & & Promedio & de Araba & \\
\hline & & Prome & edio de $A$ & ragón & & Prom & nedio de Cataluña & & & Promedio & de Navarra & \\
\hline & & Prome & edio de $A$ & ndalucía 19 & & Prom & nedio de Andalucía (t & & & Promedio & de Castilla & y León \\
\hline
\end{tabular}

${ }^{*}$ ) El coste/hora contiene, asimismo, los siguientes conceptos: Seguridad Social (33\%) y absentismo + pluses varios (10 \%).

Para el cálculo de los costes de personal la referencia es la ocupación real del centro ( $\mathrm{i}=1 \mathrm{i}=3$ ni) y no su capacidad (n). El coste de personal es conceptualmente fijo para un tamaño dado de centro y, por tanto, a menor ocupación mayor imputación por plaza por efecto de un decremento del precio medio ponderado. En nuestro análisis supondremos ocupaciones máximas con costes de personal fijos.

Fuente: Elaboración propia. 


\subsection{Costes de funcionamiento}

Por reducción a su mínima expresión, podríamos identificar este tipo de costes como aquellos que no proceden de la aplicación directa de ratios de personal. Integrados por el conjunto de costes mixtos (parte fija y parte variable como, por ejemplo, gastos de energía) y costes propiamente variables (materias primas de manutención) oscilan en el intervalo (25\%-30\%) del coste total propuesto por Gipuzkoa, con un peso específico que desciende a medida que crece el grado de dependencia y como consecuencia de una presencia de personal progresivamente mayor. El gasto de funcionamiento también es sensible a las especificidades de la atención a perfiles cada vez más dependientes pero en una relación claramente inferior a la resultante de los incrementos en las ratios de atención. Si bien estos gastos aumentan con efecto casi marginal por acceso a estadios superiores de dependencia, las necesidades de personal lo hacen de tal manera que contrarrestan el efecto y minoran el peso relativo de aquellos en el coste por plaza, a pesar de incrementar su valor absoluto.

Según IDESCAT-Instituto de Estadística de Cataluña, el porcentaje sobre costes de los gastos de funcionamiento es de un $24,9 \%$. Otros estudios como el realizado en la Comunidad Valenciana (Tortosa et al., 2013) sitúan la compra de bienes y servicios en un 18,7\%; por su parte, el análisis de las cuentas de resultados de residencias de Cantabria cifra este tipo de costes en un 32,62 \% (Díaz, B., 2012). El análisis de las cuentas de resultados de las residencias de Lares Euskadi cuantifican estos gastos en torno a un $24 \%$ del coste, entendida esta equivalencia como media de todos los grados de dependencia. Dado el objetivo del proyecto, no se observan diferencias que justifiquen un estudio analítico en mayor profundidad. Es tal la correspondencia entre coste y ratio, que hipoteca la capacidad de maniobra sobre el resto de inputs que componen la producción de servicios residenciales para personas mayores. En otras palabras, el diferencial entre precio y coste de personal debería ser tal que permitiera una atención estándar y suficiente. No obstante, un marco de obligaciones cada vez más exigente y diverso (implantación y mantenimiento de sistemas de gestión de la calidad, desarrollo de planes de prevención y seguridad, cumplimiento de normativas ambientales, presentación de auditorías contables o financieras, etc.) podría requerir una mayor dotación de gastos de funcionamiento que repercutiesen en una revisión al alza de los precios. Pero, como demostraremos, este paradigma no es de aplicación para el conjunto de normativas: disfrutar de un precio elevado no garantiza mayores márgenes de beneficio.

El análisis de los precios de diferentes años demuestra que su fijación por cada autonomía, a excepción de Gipuzkoa, no obedece a una estructura modular de cálculo que se ajuste a expresiones del tipo $\mathrm{P}=\mathrm{CP}+\mathrm{GF}+\mathrm{A}+\mathrm{B}$ ㅇ (CP: coste de personal en función de la ratio y del IPD, GF: gastos de funcionamiento, $\mathrm{A}$ : amortizaciones y $\mathrm{B}$ 을 beneficio correspondiente a un margen predeterminado). Desde las ratios de atención total -como hemos podido comprobar, nueve normativas contemplan ratios para todos los grados de dependencia y 2 para niveles I, II y III- estimamos CP para un escenario previsible y verosímil (2.3.3.). Ninguna normativa pondera el valor de GF o de A y, sin embargo, una comparativa coherente aconsejaría que ambas variables estuvieran evaluadas, al menos desde una perspectiva teórica que fuera sensible a los rasgos distintivos de cada autonomía (fundamentalmente, índice de coste de la vida y precio de construcción de nueva vivienda).

Dado que los estándares de Gipuzkoa se entienden como una referencia válida para cubrir los gastos de funcionamiento -empíricamente se constata que, en términos generales, la dotación pública garantiza suficiente financiación para costes mixtos y variables incluyendo asimismo el gasto derivado de nuevas exigencias - lo adaptaremos a las diferentes autonomías del Estado. Ajustando el módulo de cada autonomía desde el índice del coste de la vida, obtenemos la distribución de costes de funcionamiento por autonomía que muestra la Tabla 10.

Tabla 10. Estimación de gastos de funcionamiento por comunidades autónomas

\begin{tabular}{|c|c|c|c|c|c|}
\hline Comunidad & $\operatorname{PPA}_{\mathrm{r}}^{\text {DEF }\left(^{*}\right)}$ & $\begin{array}{c}\text { PPA/ } \\
\text { PPA }_{G^{(* *)}}\end{array}$ & Grado 0 & Grado I & $\begin{array}{c}\text { Grado } \\
\text { II-III } \\
\end{array}$ \\
\hline Gipuzkoa & & & $18,18^{(* * *)}$ & 20,68 & 22,44 \\
\hline Andalucía & 92,7 & 0,8607 & 15,65 & 17,80 & 19,31 \\
\hline Araba & 107,7 & 1,0000 & 18,18 & 20,68 & 22,44 \\
\hline Aragón & 96,4 & 0,8951 & 16,27 & 18,51 & 20,09 \\
\hline Asturias & 87,9 & 0,8162 & 14,84 & 16,88 & 18,31 \\
\hline Baleares & 98,9 & 0,9183 & 16,69 & 18,99 & 20,61 \\
\hline Bizkaia & 107,7 & 1,0000 & 18,18 & 20,68 & 22,44 \\
\hline Canarias & 83,1 & 0,7716 & 14,03 & 15,96 & 17,31 \\
\hline Cantabria & 99,1 & 0,9201 & 16,73 & 19,03 & 20,65 \\
\hline Castilla-La Mancha & 84,8 & 0,7874 & 14,31 & 16,28 & 17,67 \\
\hline
\end{tabular}

\begin{tabular}{|l|c|c|c|c|c|}
\hline Comunidad & PPA $_{\mathrm{r}}^{\text {DEF (*) }}$ & PPA/PPA $_{\mathbf{G}}$ & Grado o & Grado I & $\begin{array}{c}\text { Grado } \\
\text { II-III }\end{array}$ \\
\hline Castilla y León & 88 & 0,8171 & 14,85 & 16,90 & 18,34 \\
\hline Cataluña & 108,5 & 1,0074 & 18,32 & 20,83 & 22,61 \\
\hline Extremadura & 80,3 & 0,7456 & 13,55 & 15,42 & 16,73 \\
\hline Galicia & 92,4 & 0,8579 & 15,60 & 17,74 & 19,25 \\
\hline Madrid & 114,5 & 1,0631 & 19,33 & 21,99 & 23,86 \\
\hline Murcia & 94,8 & 0,8802 & 16,00 & 18,20 & 19,75 \\
\hline Navarra & 110,6 & 1,0269 & 18,67 & 21,24 & 23,04 \\
\hline La Rioja & 90,4 & 0,8394 & 15,26 & 17,36 & 18,84 \\
\hline Valencia & 93 & 0,8635 & 15,70 & 17,86 & 19,38 \\
\hline
\end{tabular}

${ }^{\star}$ ) PPA: paridad del poder adquisitivo (indicador económico para comparar el nivel de vida entre distintas autonomías).

$(\star \star)$ PPA/PPAG: ratio entre PPA de cada autonomía y PPA de Euskadi.

${ }^{* * *}$ Estimaciones para ocupación plena (con IPD«3, deberían ver reducido su importe anual para el número medio de residentes).

Fuente: Elaboración propia / Estimació de les paritats de poder adquisitiu per a les comunitats autònomes españoles (Monografies, Generalitat de Catalunya, Departament d’Economia i Coneixement). 


\subsection{Costes de amortización}

Se trata de estandarizar, en la media de lo posible y bajo criterios de verosimilitud, el porcentaje del precio que podemos estimar como representativo de la amortización de inmuebles y equipamiento. Como "a escala nacional, la información existente sobre el volumen de la inversión también difiere de unos estudios a otros" (Díaz Díaz, 2012), la referencia debería ser teórica y basada en las indicaciones recogidas desde diferentes fuentes bibliográficas o empíricas. La profesora Díaz, en su modelo de costes para las residencias de Cantabria, cuantifica el porcentaje de la amortización por inmuebles en un $6,97 \%$ y en un $2,43 \%$ en equipamiento; asimismo, la distribución modular del coste por plaza propuesto por Diputación Foral de Gipuzkoa evalúa el conjunto de la amortización y los costes financieros derivados del endeudamiento necesario para adquirir el activo fijo tangible en un $11,7 \%$ del coste por plaza. Obsérvese la proximidad entre ambos valores $(9,49 \%=6,96 \%+$ $2,43 \%$ y $11,7 \%$ ) si dedujéramos los costes financieros del módulo planteado en Gipuzkoa.

Este estudio no pretende enumerar cada uno de los elementos que componen el activo fijo de un geriátrico. Tampoco pretende diseccionar todas y cada una de las casuísticas posibles que inciden en la tasación de los costes de amortización (propiedades sin costes de adquisición, compartición de servicios en un mismo inmueble, variabilidad en las calidades de construcción, superficies mínima por plaza particulares de cada normativa, etc.). La hipótesis de partida plantea la amortización como un porcentaje más o menos fluctuante en un intervalo de amplitud razonable, idea contrastada desde el valor porcentual promedio de la amortización sobre el precio (Tabla 11). Aplicaremos la identidad $P=C P+G F+A+B=0$ para estimar costes unitarios de amortización partiendo de una normativa de referencia que desagregue el precio en sumandos modulares. En concreto, nos basaremos en la imputación sugerida por Gipuzkoa y que pondera la amortización de inmuebles y equipamiento en torno al $9 \%$ del coste por plaza (aproximadamente 8,50 euros por plaza y día).

Desde las ratios totales estimamos los costes de personal para el escenario 2.3.3.; desde la suma de módulos agrupados bajo el genérico "gastos de funcionamiento" (GF), proyectamos el modelo guipuzcoano al resto de comunidades con el factor de conversión propuesto por el índice del coste de la vida y, finalmente, desde el valor absoluto de la amortización unitaria en Gipuzkoa rectificada con el precio del metro cuadrado de construcción en la comunidad de destino, podremos teorizar sobre la relación entre amortización y precio para un margen de beneficio dado (en nuestro caso, del $5 \%$ sobre el precio).

Tabla 11. Obtención del coste teórico de amortización

\begin{tabular}{|c|c|c|c|c|c|c|c|}
\hline \multirow{2}{*}{ Comunidad } & \multirow{2}{*}{$\mathrm{CP}$} & \multirow{2}{*}{ GF } & \multicolumn{4}{|c|}{ Amortización } & \multirow{2}{*}{$\begin{array}{c}\text { Precio } \\
\text { adaptado }^{(* *)}\end{array}$} \\
\hline & & & Precio $\mathrm{m}^{2}$ & Método-1 ${ }^{(*)}$ & $\% A / P$ & Método-2 ${ }^{(\star *)}$ & \\
\hline Gipuzkoa & 67,12 & 14,36 & $2.686,20$ & 8,39 & $9,0 \%$ & & 93,22 \\
\hline Andalucía 1997 & 28,77 & 13,81 & $1.232,70$ & 4,30 & $8,7 \%$ & 3,91 & 49,35 \\
\hline Araba & 25,89 & 16,04 & $1.905,10$ & 6,19 & $12,2 \%$ & 5,73 & 50,66 \\
\hline Aragón & 20,14 & 12,85 & $1.152,80$ & 4,08 & $10,5 \%$ & 3,68 & 39,02 \\
\hline Asturias & 27,71 & 11,72 & $1.254,00$ & 4,36 & $9,5 \%$ & 3,94 & 46,10 \\
\hline Bizkaia & 35,29 & 16,04 & $2.350,50$ & 7,45 & $12,0 \%$ & 7,31 & 61,87 \\
\hline Canarias & & & $1.403,10$ & & & & \\
\hline Cantabria & 19,11 & 13,21 & $1.473,50$ & 4,98 & $12,7 \%$ & 4,62 & 39,27 \\
\hline Castilla - La Mancha & 18,21 & 11,31 & 874,20 & 3,30 & $9,5 \%$ & 2,89 & 34,55 \\
\hline Castilla y León & 26,47 & 11,73 & $1.044,80$ & 3,78 & $8,5 \%$ & 3,38 & 44,19 \\
\hline Cataluña & 21,29 & 16,16 & $1.834,00$ & 5,99 & $13,1 \%$ & 5,71 & 45,73 \\
\hline Extremadura & & & 864,50 & & & & \\
\hline Galicia & 30,98 & 12,32 & $1.186,60$ & 4,17 & $8,4 \%$ & 3,77 & 49,98 \\
\hline Islas Baleares & 26,56 & 13,19 & $2.108,20$ & 6,77 & $13,8 \%$ & 6,50 & 48,96 \\
\hline La Rioja & 24,79 & 12,05 & $1.100,90$ & 3,93 & $9,2 \%$ & 3,79 & 42,92 \\
\hline Madrid & & & $2.263,60$ & & & & \\
\hline Murcia & 14,39 & 14,12 & 971,40 & 3,57 & $10,6 \%$ & 3,20 & 33,76 \\
\hline Navarra & 20,14 & 16,47 & $1.325,40$ & 4,56 & $10,5 \%$ & 4,16 & 43,34 \\
\hline Valencia & 33,41 & 12,40 & $1.149,60$ & 4,07 & $7,8 \%$ & 3,70 & 52,51 \\
\hline & & & \multicolumn{3}{|c|}{ Correlación método 1-método 2: } & 0,9977 & \\
\hline
\end{tabular}

$\left.{ }^{\star}\right) \mathrm{A}=\mathrm{AG}^{*}\left(0,9^{\star} \mathrm{Pm} 2 / \mathrm{Pm} 2 \mathrm{G}+0,1\right) \rightarrow$ la amortización del inmueble es el producto de dicha amortización en Gipuzkoa por la relación entre el precio

\footnotetext{
de construcción del metro cuadrado de las comunidades comparadas. La amortización total se reparte a razón del $90 \%$ en inmuebles y del $10 \%$ en instalaciones y equipamiento.

${ }^{* *}$ La amortización formulada desde relaciones entre precios reales por plaza y entre precios de construcción por metro cuadrado (Gipuzkoa y comunidad comparada) propone costes teóricos unitarios de valor semejante.

$(* * *) P A=(C P+G F+A) /(1-M B) \rightarrow$ el precio adaptado es el cociente entre la suma del coste de personal (ratios totales o estimación para escenario 2.3.3), los gastos de funcionamiento y la amortización (estimados) y el peso relativo de dicha suma respeto del precio detraído en el porcentaje del margen de beneficio.
}

Fuente: Elaboración propia. 
Salvo en Araba y Bizkaia, el coste de amortización baja a medida que nos trasladamos hacia la derecha en el eje IPD; dicho de otro modo, si precisamos precios por grados de dependencia, la amortización -básicamente fija e independiente del perfil de atención- tiende a bajar.

La curva de esta progresiva pérdida de peso como componente del coste por plaza (gráfico de la Tabla 12), si el precio fuera consecuente con la evaluación de los parámetros CP, GF y A, presentaría pendientes de diferente valor para cada IPD como resultado de la previsible desviación entre precio real y precio adaptado. En todo caso y en general, según muestra la Tabla 12, los precios que prevén las autonomías son superiores a los que se proponen desde formulaciones basadas en valores estándar de GF y A; lo son, además, en una media estatal en absoluto despreciable (14,61\%). Si bien esta primera aproximación la realizamos sobre IPD máximo, comprobaremos que Gipuzkoa se constituye en arquetipo para la modulación del coste por plaza y para la correlación acompasada entre módulo principal (CP) e índice ponderado de dependencia (IPD). Aunque teóricamente pudiéramos imputar costes de amortización por tipología de dependencia desde sistemas de contabilidad analítica o modelos de coste $A B C$, la implantación de métodos tan complejos de diseñar y mantener no se justifica cuando la propia Administración no afina mínimamente el precio público. Únicamente si el mercado fuera íntegramente privado y quisiéramos desplegar tantos precios como servicios pudieran ser ofertados, asignar y distribuir costes conforme a las actividades inherentes a cada proceso de producción tendría sentido. Cuando el abanico de precios públicos se limita a tan solo 2,32 categorías de media, el empeño por extraer costes por perfiles de atención debe ser comedido para no romper el equilibrio entre los recursos destinados a este propósito (personales y materiales) y la rentabilidad obtenida en este esfuerzo.

\subsection{Composición del coste por plaza}

Se han estimado valores para los sumandos de la igualdad $C P=C P+G F+A+B$ ‥ En la práctica, hemos realizado un ejercicio teórico para componer un coste por plaza que haga viable una comparativa intercomunitaria por grados de dependencia conforme a un patrón de cálculo exportable desde Gipuzkoa al resto de comunidades. En nuestro ánimo está romper con ciertas creencias extendidas que conjeturan mayores márgenes en la red guipuzcoana que en cualquier otra red autonómica. No compartimos esta opinión para cualquiera que sea la perspectiva desde la que se pronuncia y la condicionamos a matizaciones con diferentes consecuencias cualitativas en la atención a personas mayores en centros residenciales.

Tabla 12. Desviación entre precio adaptado y precio real (IPD=3)

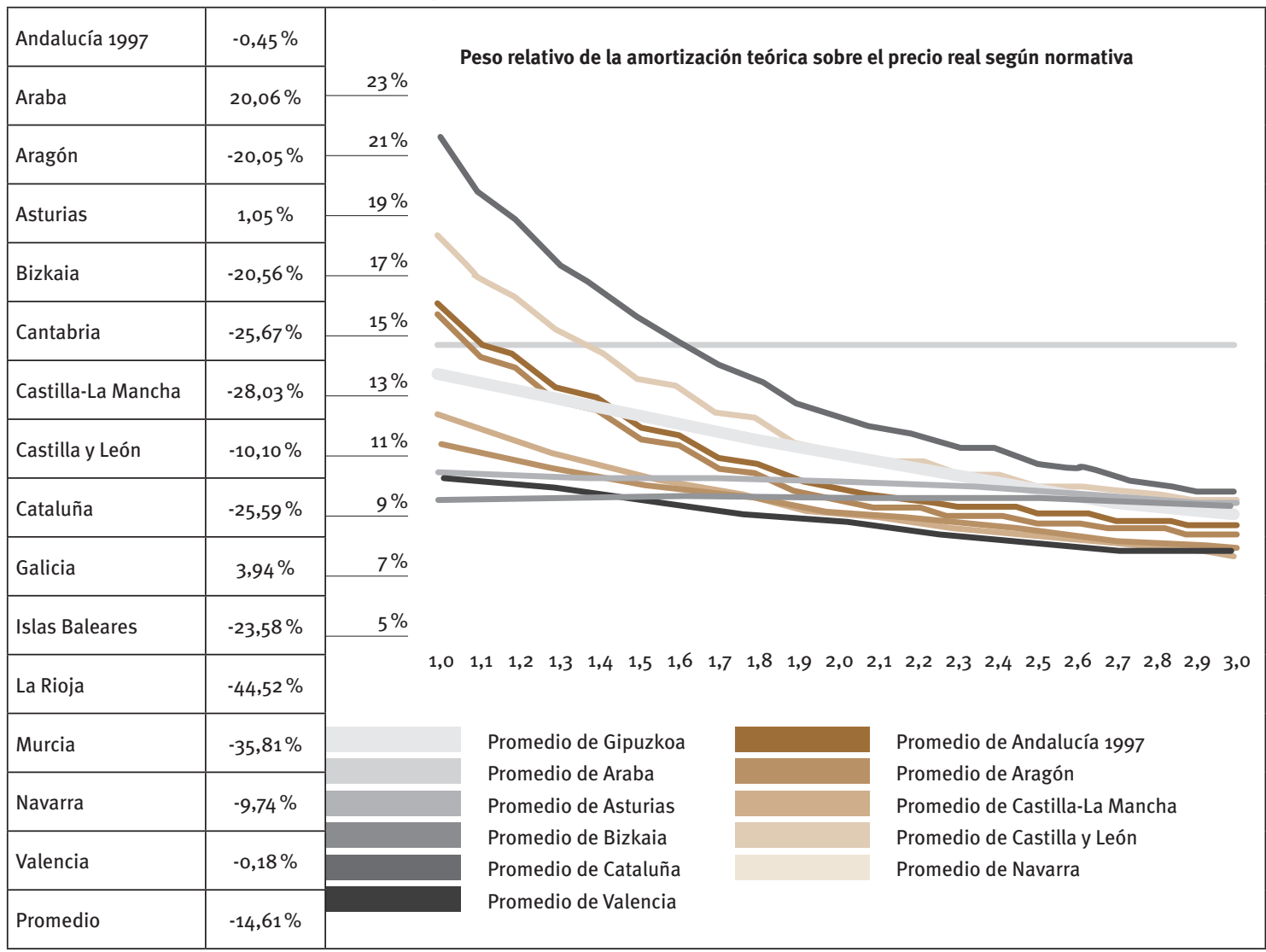

Fuente: Elaboración propia. 
Tabla 13. Incrementos de precio derivados de incrementos de coste de personal

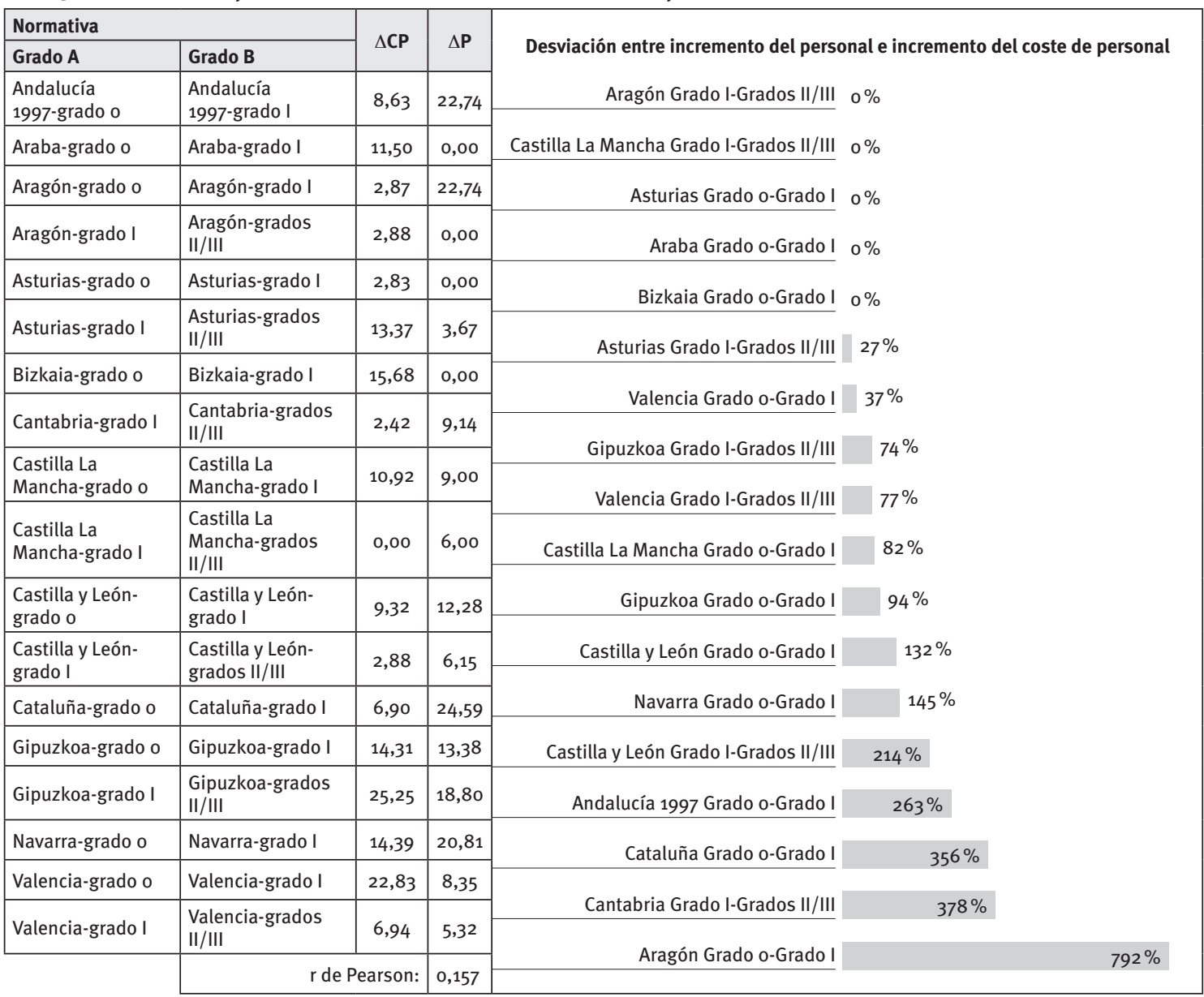

Fuente: Elaboración propia.

- El modelo guipuzcoano se fundamenta en dos pilares distintivos: altísima tasa de concertación (prácticamente del $90 \%$ del total de la red residencial) y ratios totales, directas o de gerocultor/a por encima del resto de comunidades en un $79 \%$ de los casos (valores de IPD en el intervalo cerrado $1 \leq I P D \leq 3$ ) que sube hasta un $98,9 \%$ para IPD $\geq 2,5$.

- Los costes unitarios de personal que presenta Gipuzkoa son los más elevados del mapa estatal; sin embargo, el porcentaje del coste de personal sobre el precio es inferior en un 22,4\% de las comparativas únicamente para combinaciones de dependencia con mayor peso relativo de grados o y I (aclaremos, en este sentido, que Gipuzkoa prioriza el acceso de grados II y III a su red residencial concertada, si bien La Ley 39/2006 reconoce a los ciudadanos en situación de dependencia un derecho universal y subjetivo).

- La correlación precio-coste de personal tiene una consistencia comparable a la de precio-ratio total $(0,729$ frente a 0,635). Esta supuesta cohesión desaparecería para el par precio-ratio si los grados II y III de Gipuzkoa no formaran parte de la muestra $(r=0,451)$. No obstante, salvo para un conjunto mínimo de normativas, la hipótesis que defiende un incremento de precios análogo al aumento de costes de personal derivados de las ratios totales no se sostiene. En un análisis ceteris paribus de la composición del coste por plaza (GF y A más o menos constantes), observamos que la correlación entre incrementos de precios y de personal no es significativa $(r=0,152)$, lo cual proyecta nuevamente una idea de dispersión de la que únicamente excluimos a Gipuzkoa.

- Solo Castilla-La Mancha (grado o-grado I), Valencia (grado I-grados II/III) y Gipuzkoa -en este caso, para todos los grados de dependencia- presentan incrementos de precio similares a los incrementos de personal. En otro sentido, hay tantas normativas que presentan $\Delta \mathrm{P}-\Delta \mathrm{CP}<0$ como $\Delta \mathrm{P}-\Delta \mathrm{CP}>0$, con una tendencia clara hacia crecimientos casi exponenciales para las relaciones positivas (la prueba $\chi^{2}$ al nivel de confianza del $99,9 \%$ acepta la hipótesis nula y demuestra la independencia entre ambas variables),

- El resultado de esta independencia entre precio y personal para un coste de amortización dado es evidente: a medida que progresa la relación entre precio y personal $(\Delta \mathrm{P} / \Delta \mathrm{CP})$ aumenta la dotación teórica por plaza para gastos de funcionamiento 


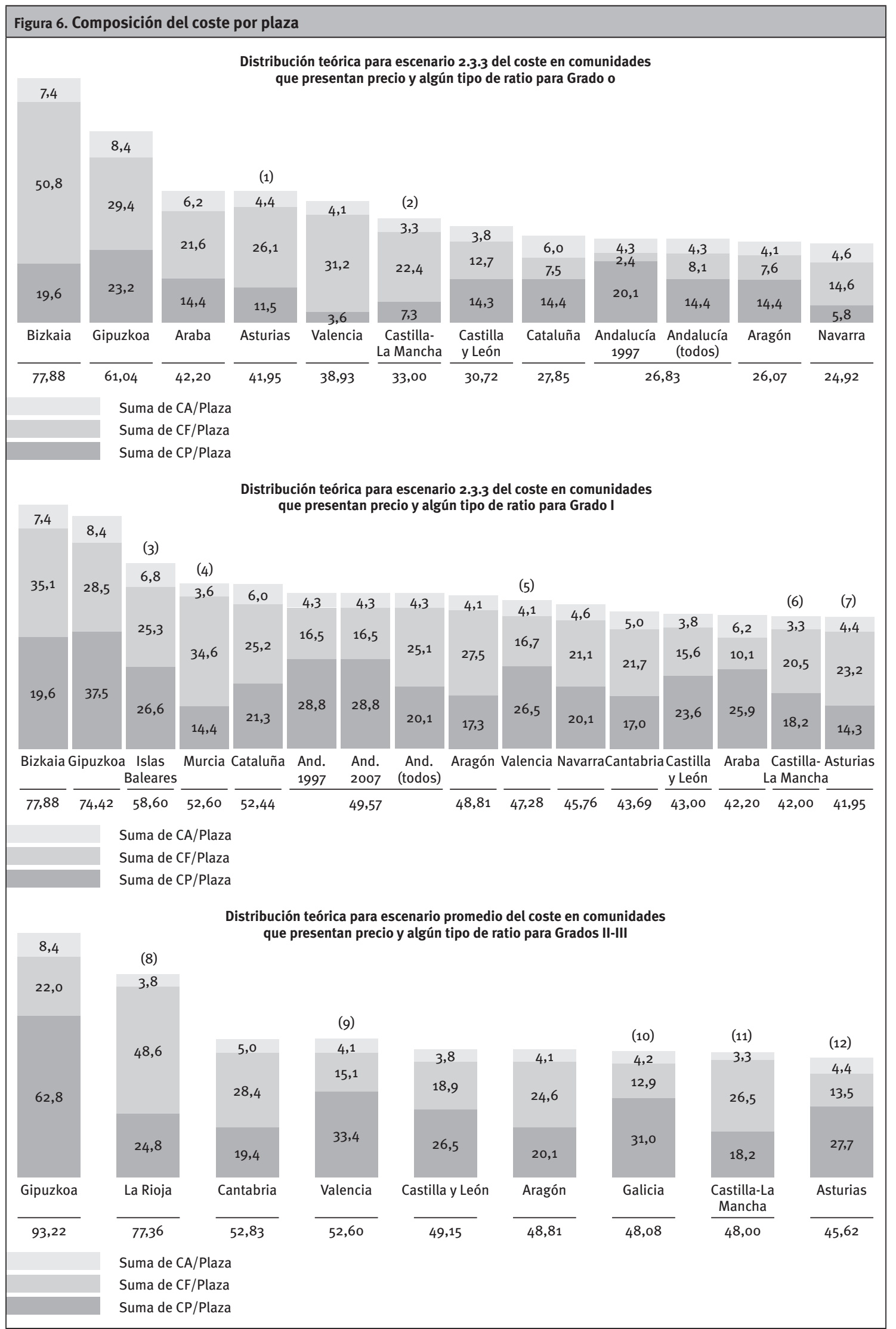

Estimaciones del coste de personal (escenario 2.3.3):

Grado 0: (1) Ratio de atención directa / (2) Ratio de gerocultor/a

Grado I: $\quad$ (3), (4), (5) y (6) Ratio de gerocultor/a / (7) Ratio de atención directa

Grados II y III: (8), (9) y (11) Ratios de gerocultor/a / (10) y (12) Ratios de atención directa

Fuente: Elaboración propia. 
y, una vez cubiertos los estándares para ellos, se obtienen mayores diferenciales que mejoran la rentabilidad sobre el precio.

- No discriminar precios por grado de dependencia, aun cuando la normativa exija ratios conforme a dichos grados, podría suponer $-\mathrm{y}$ de hecho supone- que en determinadas autonomías/ territorios la composición del mix de atención (IPD), si bien incide en la estructura del coste, nunca plantee problemas de financiación (casos de Bizkaia y Murcia). Por otra parte, esta garantía no se disfruta en la tercera comunidad con precio único: Araba. Este territorio foral vería comprometida la viabilidad económica de centros con predominio de plazas concertadas e IPD>1 si no contuviera drásticamente los costes de funcionamiento.

- El coste $(C=C P+G F+A)$ no es flexible en las partes que lo componen. Las organizaciones tienen una capacidad de maniobra limitada sobre el valor de los sumandos CP y A: minimizar la tasa de absentismo desde la incidencia positiva de determinadas políticas de personal y la construcción de inmuebles con financiación ajena altruista y a fondo perdido. En consecuencia, desde la eficiencia en el consumo de insumos diferentes a los recursos humanos determinaremos fundamentalmente la sostenibilidad futura de las organizaciones. En la medida que minore el peso específico de los costes de funcionamiento sobre el coste por plaza (Suma de CF/plaza de la Figura 6) deberemos optimizar al máximo la gestión de dichos costes.

- Se manifiesta una incontestable descompensación entre las distintas estructuras teóricas de coste obtenidas desde la interpretación de las diferentes normativas. Es más que probable que la realidad asistencial del Estado no mantenga un paralelismo con el mapa descrito. La evolución en los perfiles de atención demanda nuevos marcos de actuación que las organizaciones gestoras se han preocupado por desarrollar sin dejar prácticamente nada al albur. En muchos casos, son normas obsoletas que no han sido dotadas de inercia suficiente para adaptarse a los permanentes cambios del sector y cuyas carencias son cubiertas desde una iniciativa privada imaginativa para evitar infinidad de contingencias perniciosas.

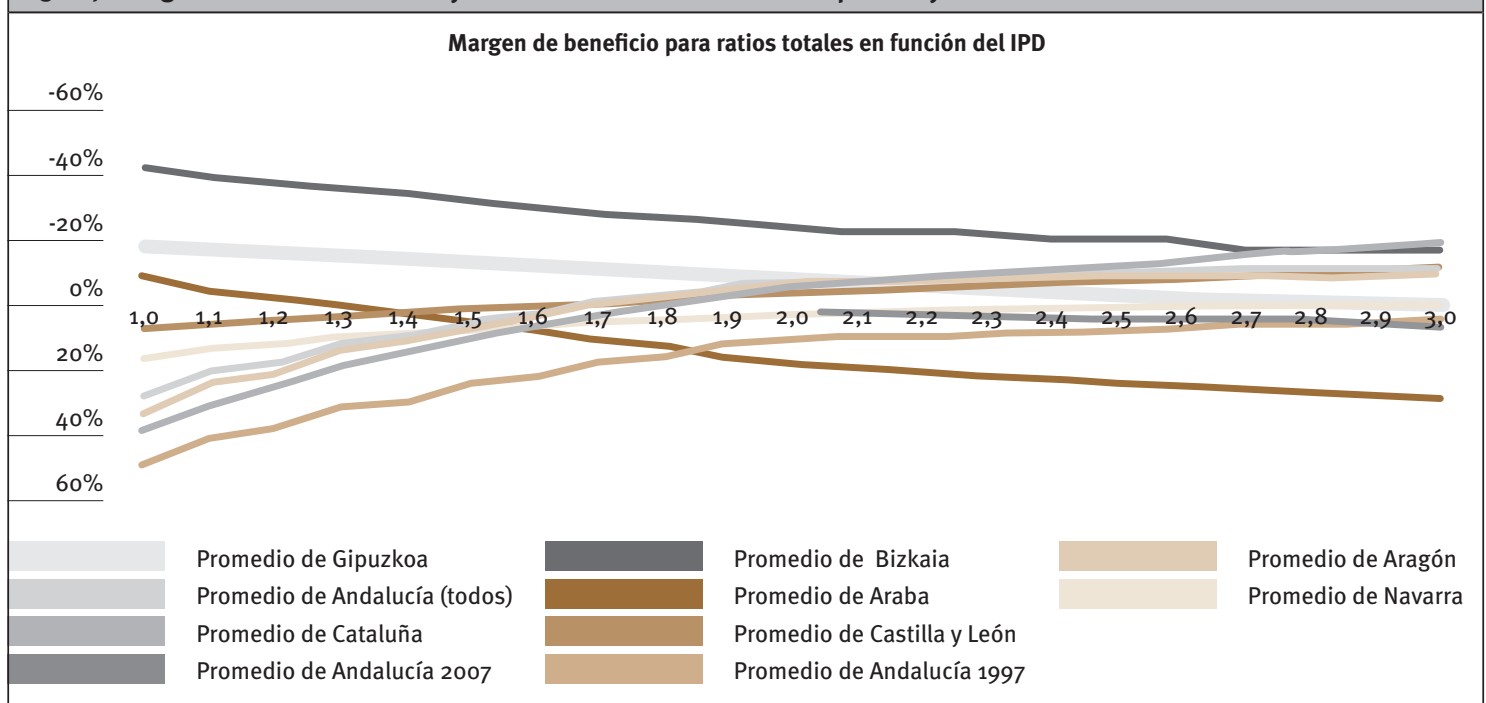

\begin{tabular}{|l|l|c|c|}
\hline \multicolumn{4}{|l|}{ Determinación del IPD frontera (Gipuzkoa frente al resto) } \\
\hline Normativa & IPD frontera & †IPD & AIPD \\
\hline Bizkaia & Siempre por encima & & \\
\hline Andalucía 2007 & Siempre por debajo & & \\
\hline Andalucía 1997 & Siempre por debajo & & \\
\hline Andalucía (todos) & 2,09 & Mejor & Peor \\
\hline Araba & Siempre por debajo & & \\
\hline Aragón & 2,09 & Mejor & Peor \\
\hline Cataluña & 2,12 & Mejor & Peor \\
\hline Castilla y León & 2,27 & Mejor & Peor \\
\hline Navarra & 2,94 & Mejor & Peor \\
\hline
\end{tabular}

\begin{tabular}{|c|c|}
\hline \multicolumn{2}{|c|}{ Determinación del IPD de umbral de rentabilidad } \\
\hline Normativa & Umbral rentabilidad \\
\hline Gipuzkoa & IPD $<2,94 \rightarrow B^{\circ}>0$ \\
\hline Bizkaia & Siempre beneficio \\
\hline Andalucía 2007 & Nunca beneficio \\
\hline Andalucía 1997 & Nunca beneficio \\
\hline Andalucía (todos) & IPD $>1,66 \rightarrow B^{0}>0$ \\
\hline Araba & $I P D<1,30 \rightarrow B^{0}>0$ \\
\hline Aragón & IPD>1,45 $\rightarrow \mathrm{B}^{0}>0$ \\
\hline Cataluña & IPD $>1,82 \rightarrow B^{0}>0$ \\
\hline Castilla y León & $\mid P D>1,63 \rightarrow B^{0}>0$ \\
\hline Navarra & IPD>2,73 $\rightarrow B^{0}>0$ \\
\hline
\end{tabular}

Fuente: Elaboración propia. 
Llegados a este punto, solo nos quedaría armar un entramado que conjugando precios, costes de personal, costes de funcionamiento y amortizaciones para una secuencia creciente de diferentes combinaciones de grados de dependencia, estime posibles márgenes de beneficio para escenarios verosímiles de personal. La inexistencia de precios modulados desde las propias Administraciones Públicas impone la estimación de costes de funcionamiento desde estandarizaciones soportadas en el modelo de Gipuzkoa. Como comprobaremos, aun cuando hemos identificado el escenario 2.3.3. como más verosímil, la presencia de otros escenarios tampoco provoca una falta de financiación generalizada. Para índices IPD consecuentes con el actual perfil promedio de atención (salvo Araba, Andalucía-1997, Andalucía-2007 y muy probablemente Navarra), los precios cubren con garantías suficientes las ratios previstas en aquellas normativas que permiten simular valores de IPD en la medida que discriminan grados de dependencia.

La importancia del índice ponderado de dependencia se revela nuclear. Por mínima que sea la distinción de perfiles de atención, estén o no sujetos a precios asociados, la composición del mix determina absolutamente la constitución del coste por plaza. Además, cualquiera que sea la distribución de grados de dependencia, es posible calcular IPD. Vista la altísima correlación de este índice con el precio y el coste de personal podemos validar el uso de funciones f(IPD) para simular diferentes escenarios de comparación.

La dispersión es una realidad innegable. No por ello, sin embargo, deberíamos concluir que los precios de Gipuzkoa -superiores al resto para IPD $\geq 2,25-$ garantizan mayor capacidad de respuesta ante futuros incrementos de coste (actualización salarial de convenios colectivos, tasas de absentismo laboral, nuevas exigencias en normativas, etc.). Si definiéramos el índice potencial de beneficio (IPB) como un cociente cuyo numerador y denominador fueran, respectivamente, el diferencial entre precio y costes de personal y amortización y el margen de beneficio sobre el precio (IPB=P-CP-AMB*P), el panorama estatal cambiaría sustancialmente sobre nuestras apreciaciones a priori. Gipuzkoa, a la cabeza en cuantas comparaciones se han propuesto (precios, horas anuales de atención, consistencia en la relación precio-ratio y equilibrio de la estructura de costes), ve afectada su posición de privilegio por efecto de una modulación del coste por plaza que condiciona la prestación del servicio con unos repartos predeterminados. Simulemos los resultados de IPB para un margen de beneficio del $5 \%$ y para incrementos secuenciales en la distribución de los grados de dependencia a intervalos de diez unidades, tal y como refleja la Tabla 14.

Tabla 14. Índices potenciales de beneficio (estimación de costes de personal de las ratios disponibles siguiendo la secuencia Total $\rightarrow$ Directa $\rightarrow$ Gerocultor $/$ a)

\begin{tabular}{|c|c|c|c|c|c|c|c|c|c|c|c|c|c|c|c|c|c|c|c|c|c|}
\hline \multicolumn{4}{|c|}{ Mix } & \multicolumn{10}{|c|}{ Totales } & \multicolumn{4}{|c|}{ Atención directa } & \multicolumn{4}{|c|}{ Gerocultor/a } \\
\hline A & D & GD & IDP & Gip. & Bizk. & $\begin{array}{l}\text { And. } \\
1997\end{array}$ & $\begin{array}{c}\text { And. } \\
\text { (todos) }\end{array}$ & Araba & Arag. & $\begin{array}{c}\text { Cast. y } \\
\text { León }\end{array}$ & Cat. & Nav. & $\begin{array}{l}\text { And. } \\
2007\end{array}$ & Ast. & Cant. & Gal. & Murcia & $\begin{array}{l}\text { Cast.-La } \\
\text { Mancha }\end{array}$ & Val. & $\begin{array}{c}\text { La } \\
\text { Rioja }\end{array}$ & I. Bal. \\
\hline \multicolumn{4}{|c|}{ Grado o } & 0,262 & 0,250 & 0,350 & 0,250 & 0,250 & 0,200 & 0,248 & 0,250 & 0,100 & & 0,130 & & & & 0,067 & 0,033 & & \\
\hline \multicolumn{4}{|c|}{ Grado I } & 0,423 & 0,450 & 0,500 & 0,350 & 0,450 & 0,300 & 0,410 & 0,370 & 0,350 & 0,500 & 0,162 & 0,295 & & 0,250 & 0,167 & 0,242 & & 0,300 \\
\hline \multicolumn{4}{|c|}{ Grados II-III } & 0,708 & 0,450 & 0,500 & 0,350 & 0,450 & 0,350 & 0,460 & 0,370 & 0,350 & 0,500 & 0,313 & 0,337 & 0,350 & & 0,167 & 0,306 & 0,280 & 0,300 \\
\hline 100 & 0 & 0 & 1,00 & 9,64 & 13,05 & 1,78 & 6,07 & 10,25 & 5,83 & 8,18 & 5,36 & 11,73 & & 12,43 & & & & 13,30 & 16,04 & & \\
\hline 90 & 0 & 10 & 1,20 & 8,93 & 12,65 & 2,61 & 6,76 & 9,70 & 6,57 & 8,42 & 6,50 & 11,37 & & 11,73 & & & & 12,95 & 14,69 & & \\
\hline 90 & 10 & 0 & 1,10 & 9,40 & 12,65 & 2,61 & 6,76 & 9,70 & 6,77 & 8,20 & 6,10 & 11,30 & & 12,30 & & & & 12,83 & 14,97 & & \\
\hline
\end{tabular}

\begin{tabular}{|c|c|c|c|c|c|c|c|c|c|c|c|c|c|c|c|}
\hline 40 & 50 & 10 & 1,70 & 7,96 & 10,64 & 5,36 & 9,06 & 6,97 & 9,69 & 8,47 & 8,73 & 9,94 & 11,06 & 10,96 & 10,06 \\
\hline 40 & 60 & 0 & 1,60 & 8,36 & 10,64 & 5,36 & 9,06 & 6,97 & 9,83 & 8,29 & 8,49 & 9,88 & 11,62 & 10,82 & 10,25 \\
\hline 30 & 0 & 70 & 2,40 & 5,81 & 10,23 & 5,74 & 9,37 & 6,43 & 9,29 & 9,46 & 10,19 & 10,08 & 7,77 & 11,40 & 8,23 \\
\hline
\end{tabular}

\begin{tabular}{|c|c|c|c|c|c|c|c|c|c|c|c|c|c|c|c|}
\hline 20 & 70 & 10 & 1,90 & 7,62 & 9,83 & 6,07 & 9,65 & 5,88 & 10,49 & 8,49 & 9,30 & 9,56 & 10,79 & 10,29 & 8,44 \\
\hline 20 & 80 & 0 & 1,80 & 7,99 & 9,83 & 6,07 & 9,65 & 5,88 & 10,62 & 8,32 & 9,10 & 9,51 & 11,35 & 10,15 & 8,61 \\
\hline 10 & 0 & 90 & 2,80 & 5,06 & 9,43 & 6,38 & 9,91 & 5,34 & 9,84 & 9,69 & 10,85 & 9,82 & 6,54 & 11,01 & 6,53 \\
\hline
\end{tabular}

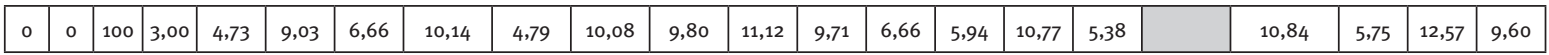

\begin{tabular}{|c|c|c|c|c|c|c|c|c|c|c|c|c|c|c|c|c|c|c|c|}
\hline 0 & 80 & 20 & 2,20 & 6,96 & 9,03 & 6,66 & 10,14 & 4,79 & 11,02 & 8,67 & 9,94 & 9,31 & 6,66 & 9,98 & 10,13 & & 9,82 & 6,79 & 8,84 \\
\hline 0 & 90 & 10 & 2,10 & 7,30 & 9,03 & 6,66 & 10,14 & 4,79 & 11,14 & 8,51 & 9,77 & 9,26 & 6,66 & 10,53 & 10,04 & & 9,68 & 6,93 & 8,73 \\
\hline 0 & 100 & 0 & 2,00 & 7,66 & 9,03 & 6,66 & 10,14 & 4,79 & 11,26 & 8,34 & 9,59 & 9,20 & 6,66 & 11,08 & 9,94 & 13,17 & 9,53 & 7,08 & 8,63 \\
\hline
\end{tabular}


El IPB mide la cantidad de euros disponibles por euro de beneficio que pretendemos conseguir, suponiendo que el diferencial P-CP-A permita cubrir los costes estándares de funcionamiento adaptados a cada autonomía. La influencia de IPD sobre IPB es más o menos determinante en función de la acción conjunta de la identificación de grados de dependencia y del valor de las ratios para los mismos. Como corroboran los siguientes gráficos, la normativa de Gipuzkoa garantiza la cobertura del coste en condiciones normales pero a medida que incrementa la dependencia opera con márgenes menores (pasa de IPB=9,6 para IPD=1 a $I P B=4,7$ para $I P D=3)$. Para el resto de normativas, se aprecian dos evolutivos diferenciados: crecimiento y decrecimiento de índices potenciales de beneficio.

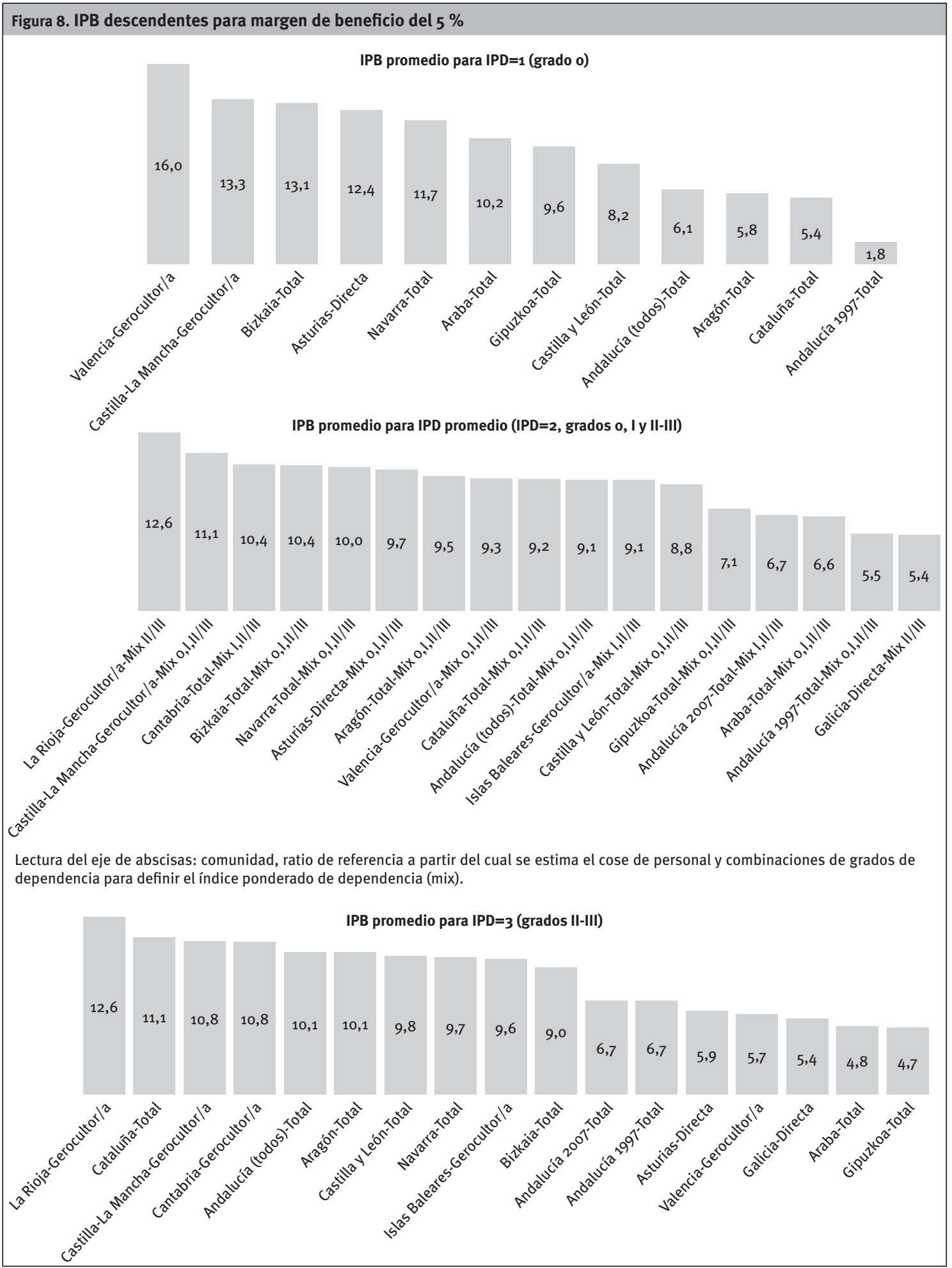

Fuente: Elaboración propia. 
Tabla 15. Funciones de incremento y decremento del IPB en función del IPD

\begin{tabular}{|l|c|c|}
\hline \multicolumn{3}{|l|}{ IPB creciente } \\
\hline Normativa & IPB $_{\text {IPD }=3^{\prime}} /$ IPB $_{\mid \mathbf{I P D}=1}$ & Máximo \\
\hline Andalucía (todos) & $10,14 / 6,07=1,67$ & 2,711 \\
\hline Andalucía 1997 & $6,66 / 1,78=3,74$ & 2,710 \\
\hline Aragón & $10,08 / 5,83=1,73$ & 2,480 \\
\hline Baleares & $9,60 / 8,63=1,11$ & 8,113 \\
\hline Cantabria & $10,77 / 9,94=1,08$ & 5,135 \\
\hline Cataluña & $11,12 / 5,36=2,07$ & 3,118 \\
\hline
\end{tabular}

\begin{tabular}{|l|c|c|}
\hline \multicolumn{3}{|l|}{ IPB decreciente } \\
\hline Normativa & IPB $_{\mid \mathbf{P D}_{3}} / \mathbf{I P B}_{\mathbf{I P D}=1}$ & Máximo \\
\hline Araba & $4,79 / 10,25=0,47$ & 3,092 \\
\hline Asturias & $5,94 / 12,43=0,48$ & $-0,096$ \\
\hline Bizkaia & $9,03 / 13,05=0,69$ & 3,092 \\
\hline Castilla - La Mancha & $10,84 / 13,30=0,82$ & 2,445 \\
\hline Gipuzkoa & $4,70 / 9,60=0,49$ & 20,249 \\
\hline Navarra & $9,71 / 11,73=0,83$ & 2,496 \\
\hline
\end{tabular}

(*) Única normativa con regresión convexa; por tanto, el máximo es realmente mínimo, en todo caso fuera del recorrido de IPD.

Fuente: Elaboración propia.

Interpretemos los valores de IPB correspondientes a $I P D=3$ e IPD=1:

- Algunas normativas permiten alcanzar ininterrumpidamente mayores cotas de beneficio teórico conforme accedemos a grados superiores de dependencia (Baleares, Cantabria, Cataluña y Castilla y León, con presencia de máximos fuera del intervalo $1 \leq \mathrm{IPD} \leq 3$ ). Podría enunciarse la misma idea para las dos normativas andaluzas que consiguen su IPB máximo para IPD=3 (el polinomio de regresión es consecuencia de incrementos marginales cada vez menores y por esta razón presume un máximo para IPD $=2,71$ ). Aragón, por su parte, plantea un IPB máximo para $I P D=2,48$ que apenas difiere de otros IPB en el intervalo $2 \leq \mathrm{IPD} \leq 3$.

- En general, los IPB decrecientes son continuos en todo el recorrido de IPD a excepción de Castilla-La Mancha y Navarra. Si bien ambas comunidades distinguen tres precios y dos perfiles de atención, la menor diferencia entre precios de grados I y II-III que entre precios de grados o y I provoca pendientes próximas a cero en la curva de regresión para $I P D \geq 2$ o, lo que es lo mismo, índices IPB prácticamente constantes (Castilla-La Mancha muestra IPB mínimo de 10,56 y máximo de 10,84; Navarra, respectivamente, de 9,77 y 9,71).

- Observemos, en todo caso, la simetría entre el índice IPB y el gráfico de la Tabla 13. Aquellas normativas con mayores relaciones $\Delta \mathrm{P} / \Delta \mathrm{CP}$ integran casi en exclusividad la relación de IPB crecientes; paralelamente, las normativas situadas en la mitad izquierda de dicho gráfico conforman el conjunto de IPB decrecientes.

\section{Comparativas intercomunitarias: proyectando el modelo de Gipuzkoa}

El presente trabajo de investigación ha pretendido delimitar un paradigma para la comparativa de normativas conforme a una misma expresión del coste por plaza. Somos conscientes de que la realidad podría ser $-\mathrm{y}$ muy probablemente lo sea-sustancialmente diferente de lo que preconiza nuestro modelo teórico. Aunque hayamos insistido sobradamente en esta idea, acreditaremos su validez
Estructura de costes: contextualizando la función $P=f\left(r_{t}, C H, G F, A, M B\right)$

- El mapa de precios del Estado parece ser más resultado de la capacidad presupuestaria de cada autonomía/territorio que consecuencia del estudio analítico del coste por plaza y la aplicación de funciones coherentes con el valor esperado para $r_{t}, C H, G F, A$ y MB,

- La fijación de precios comparativamente elevados no garantiza, por sí misma, una mayor capacidad para prestar el servicio en las condiciones previstas por cada normativa.

- El cociente $\Delta \mathrm{P} / \Delta \mathrm{CP}$ que, a su vez, depende de la discriminación y del valor de las ratios de personal, es la variable que determina el verdadero potencial del precio para cumplir con los requisitos asistenciales (recursos humanos) y materiales (costes de funcionamiento y de amortización) en disposición de obtener unos mínimos beneficios que garanticen la sostenibilidad de los centros.

- Podemos concluir que, a excepción de Andalucía 1997 y 2007, los precios permiten cubrir las exigencias de normativa a partir de valores IPD bastante verosímiles en las actuales circunstancias de atención (perfiles muy demandantes). Ello no significa, sin embargo, que las ratios sean suficientes para responder de lo que realmente necesitan las personas mayores dependientes usuarias de servicios residenciales.

- Gipuzkoa sobresale en precio, ratio y consistencia de la relación entre ambas variables; no es, sin embargo, terreno abonado para lucrarse con altas rentabilidades por euro invertido. 
desde la evidencia empírica: por ejemplo, una proporción considerable de centros asociados a Lares Euskadi han diseñado plantillas de personal muy por encima de las exigencias contempladas en el Decreto 41/1998 del Gobierno Vasco. A pesar de este hecho innegable y presumiblemente extensible en parte al conjunto de autonomías del Estado, defendemos que este tipo de estudios son necesarios para entender mejor el subsector de las residencias para personas mayores y poder dotarlo de una inercia orientada a recortar las diferencias asistenciales y económicas; o, como mínimo, para ser conscientes de ellas y dinamizar las voluntades políticas para acercarse a las comunidades referentes en un anhelo por cumplir con el principio de solidaridad interterritorial. Una pobrísima voluntad política que, por otra parte, obstinadamente insiste en incumplir los acuerdos y compromisos derivados de la Ley 39/2006 en un alarde de inoperancia gestora y de ausencia de compromiso real y evidenciable con los más desfavorecidos.

Veamos la incidencia del modelo guipuzcoano en cada normativa en vigor y las diferencias que se producen en la composición del precio para costes estandarizados de funcionamiento y amortización y un margen de beneficio del $5 \%$ (Tabla 16).

Aproximadamente en tres cuartas partes de los casos $(73,5 \%)$ con precios de referencia en normativa, el modelo de Gipuzkoa plantea un incremento de los mismos con diferente intensidad. La traslación, realizada conforme a la aplicación de las ratios totales guipuzcoanas para el escenario de personal 2.3.3., ofrece unos resultados que confirman un sorprendentemente escaso incremento medio para los grados o y I (2,57 y 1,26 euros por plaza y día respectivamente) acompañado de un previsible incremento para los grados II-III (16,53 euros). Bizkaia resta efecto al conjunto del Estado porque presenta precios sustancialmente más altos que los derivados desde Gipuzkoa. Si anuláramos la influencia de Bizkaia, el crecimiento medio alcanzaría los 5,76 euros para grados o y, aunque su efecto no se haga especialmente patente, el precio medio para grados I aumentaría poco más de un euro (2,30 euros). Estas cifras absolutas difieren ostensiblemente de las desviaciones porcentuales entre costes según normativa y costes proyectados desde Gipuzkoa, especialmente en lo referido a costes de personal que registran variaciones considerables (hasta de un $69,8 \%$ para grados II y III).

Los precios trazados conforme a criterios guipuzcoanos son superiores en términos medios para grados II-III, guardando cierto paralelismo para grados o y l. Aunque el porcentaje de precios con menor valor afecta a un $\mathbf{2 6 , 7} \%$ de las combinaciones precio-grado proyectadas, su influencia es tal que ofrece un panorama en el que la aplicación del modelo guipuzcoano no garantiza un incremento del precio medio real, en buena parte por el peso de

Tabla 16. Comparativa entre precios de normativa y precios desde proyección del modelo de Gipuzkoa (proyección > normativa)

\begin{tabular}{|c|c|c|c|c|c|c|c|c|c|c|c|c|c|c|c|}
\hline & \multicolumn{5}{|c|}{ Grado o } & \multicolumn{5}{|c|}{ Grado I } & \multicolumn{5}{|c|}{ Grados II-III } \\
\hline & \multirow{3}{*}{ Normativa } & \multicolumn{4}{|c|}{ Proyección } & \multirow{3}{*}{ Normativa } & \multicolumn{4}{|c|}{ Proyección } & \multirow{3}{*}{ Normativa } & \multicolumn{4}{|c|}{ Proyección } \\
\hline & & \multirow{2}{*}{ Precio } & \multicolumn{3}{|c|}{ Diferencias } & & \multirow{2}{*}{ Precio } & \multicolumn{3}{|c|}{ Diferencias } & & \multirow{2}{*}{ Precio } & \multicolumn{3}{|c|}{ Diferencias } \\
\hline & & & $\mathrm{CP}(*)$ & $\mathrm{GF}+\mathrm{A}+\mathrm{B}^{\circ}$ & Neto & & & $\mathrm{CP}$ & $G F+A+B^{\circ}$ & Neto & & & $\mathrm{CP}$ & $\mathrm{GF}+\mathrm{A}+\mathrm{B}^{\circ}$ & Neto \\
\hline Andalucía 1997 & 26,83 & 36,87 & $-5,07$ & 15,10 & 10,04 & 49,57 & 48,91 & $-4,41$ & 3,75 & $-0,66$ & 49,57 & 67,75 & 11,97 & 6,21 & 18,18 \\
\hline Andalucía 2007 & 26,83 & 36,87 & & & & 49,57 & 48,91 & $-4,41$ & 3,75 & $-0,66$ & 49,57 & 67,75 & 11,97 & 6,21 & 18,18 \\
\hline $\begin{array}{l}\begin{array}{l}\text { Andalucía } \\
\text { (todos) }\end{array} \\
\end{array}$ & 26,83 & 36,87 & 0,69 & 9,35 & 10,04 & 49,57 & 48,91 & 4,22 & $-4,88$ & $-0,66$ & 49,57 & 67,75 & 20,60 & $-2,42$ & 18,18 \\
\hline Araba & 42,20 & 41,52 & 0,69 & $-1,36$ & $-0,67$ & 42,20 & 53,93 & $-1,54$ & 13,27 & 11,73 & 42,20 & 73,03 & 14,85 & 15,98 & 30,83 \\
\hline Aragón & 26,07 & 37,29 & 0,69 & 10,53 & 11,22 & 48,81 & 49,42 & 7,10 & $-6,49$ & 0,61 & 48,81 & 68,32 & 20,60 & $-1,09$ & 19,51 \\
\hline Asturias & 41,95 & 36,08 & 3,56 & $-9,43$ & $-5,87$ & 41,95 & 48,00 & 10,02 & $-3,96$ & 6,05 & 45,62 & 66,76 & 13,03 & 8,11 & 21,14 \\
\hline Bizkaia & 77,88 & 48,60 & 0,94 & $-30,22$ & $-29,28$ & 77,88 & 64,55 & $-2,09$ & $-11,24$ & $-13,33$ & 77,88 & 89,91 & 20,24 & $-8,21$ & 12,03 \\
\hline \multicolumn{16}{|l|}{ Canarias } \\
\hline Cantabria & & & & & & 43,69 & 50,91 & 7,36 & $-0,14$ & 7,22 & 52,83 & 69,87 & 21,34 & $-4,30$ & 17,04 \\
\hline $\begin{array}{l}\text { Castilla - La } \\
\text { Mancha }\end{array}$ & 33,00 & 34,40 & 7,79 & $-6,38$ & 1,40 & 42,00 & 46,25 & 6,14 & $-1,89$ & 4,25 & 48,00 & 64,96 & 22,53 & $-5,57$ & 16,96 \\
\hline Castilla y León & 30,72 & 35,48 & 0,80 & 3,95 & 4,76 & 43,00 & 47,40 & 0,77 & 3,63 & 4,40 & 49,15 & 66,16 & 14,27 & 2,74 & 17,01 \\
\hline Cataluña & 27,85 & 41,45 & 0,69 & 12,92 & 13,60 & 52,44 & 53,88 & 3,07 & $-1,63$ & 1,44 & 61,46 & 72,99 & 19,45 & $-7,92$ & 11,53 \\
\hline \multicolumn{16}{|l|}{ Extremadura } \\
\hline Galicia & & & & & & & & & & & 48,08 & 67,86 & 10,06 & 9,72 & 19,78 \\
\hline Islas Baleares & & & & & & 58,60 & 52,75 & $-2,20$ & $-3,65$ & $-5,85$ & 64,06 & 71,70 & & & \\
\hline La Rioja & & & & & & 60,14 & 47,73 & & & & 77,36 & 66,31 & 15,44 & $-26,49$ & $-11,05$ \\
\hline \multicolumn{16}{|l|}{ Madrid } \\
\hline Murcia & & & & & & 52,60 & 48,56 & 9,97 & $-14,01$ & $-4,04$ & 52,60 & 67,44 & & & \\
\hline Navarra & 24,95 & 40,32 & 9,32 & 6,06 & 15,38 & 45,76 & 52,80 & 4,22 & 2,82 & 7,04 & 48,02 & 71,95 & 20,60 & 3,33 & 23,93 \\
\hline Valencia & 38,93 & 36,60 & 0,61 & $-2,94$ & $-2,33$ & 47,28 & 48,59 & $-2,24$ & 3,55 & 1,32 & 52,60 & 67,35 & 7,13 & 7,62 & 14,75 \\
\hline $\begin{array}{l}\text { Variaciones } \\
\text { medias } \\
\text { absolutas }\end{array}$ & & 1,88 & 0,69 & 2,57 & & & 2,40 & $-1,14$ & 1,26 & & & 16,27 & 0,26 & 16,53 & \\
\hline $\begin{array}{l}\text { Variaciones } \\
\text { medias } \\
\text { relativas }\end{array}$ & & $28,0 \%$ & $38,0 \%$ & $17,2 \%$ & & & $15,3 \%$ & $1,6 \%$ & $4,17 \%$ & & & $69,8 \%$ & $12,7 \%$ & $34,0 \%$ & \\
\hline
\end{tabular}

${ }^{*}$ ) Costes de personal para la proyección del modelo de Gipuzkoa calculados desde la adaptación de las ratios a las jornadas anuales de los convenios de referencia $\left(r_{i}=r_{i}^{*} j_{j} / 1592\right.$, donde $r_{i}$ y $J_{i}$ son, respectivamente, la ratio equivalente y la jornada laboral anual en la comunidad comparada y $r_{i}$ la ratio de Gipuzkoa para cada grado de dependencia).

Fuente: Elaboración propia. 


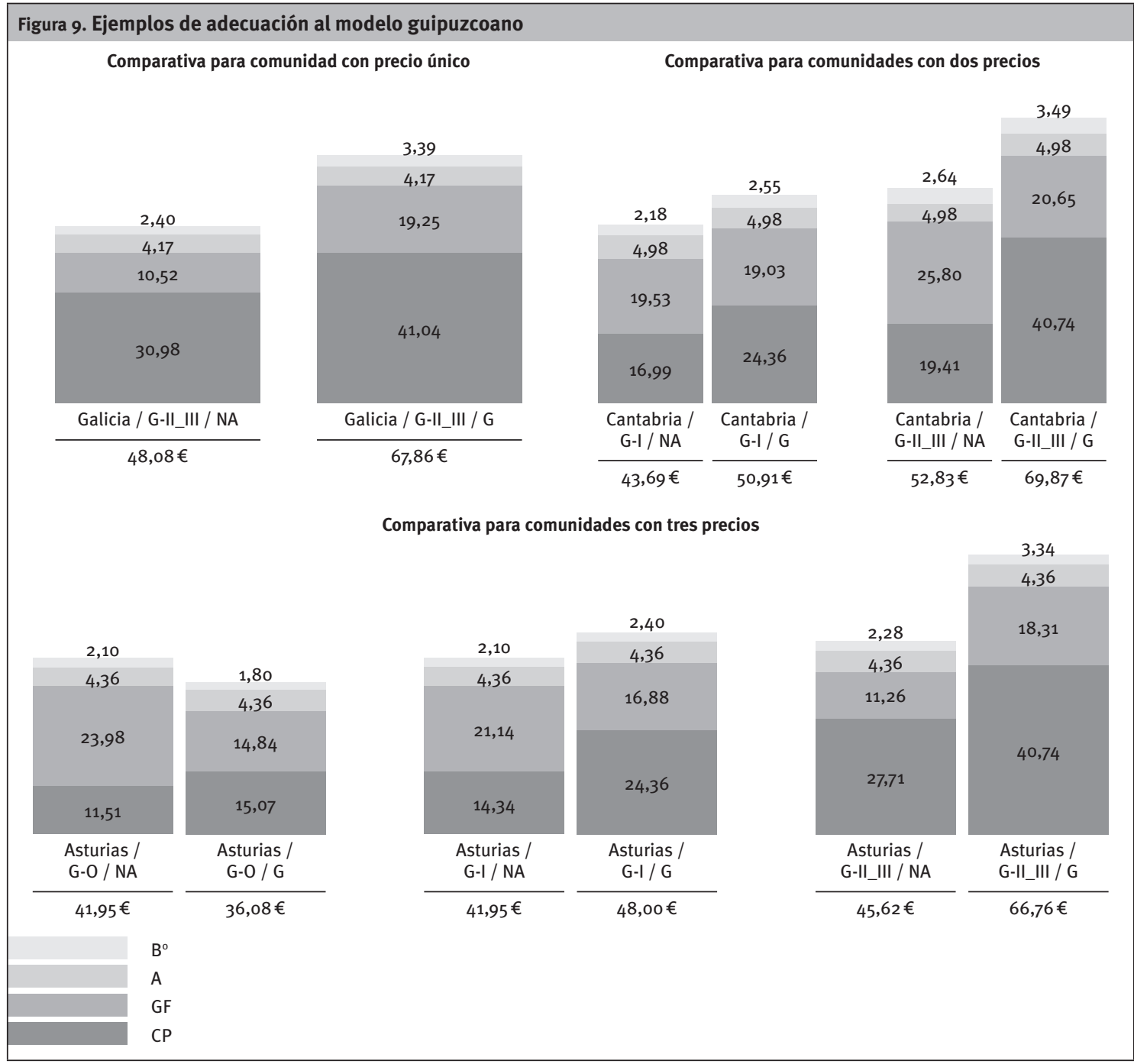

Leyenda: NA - normativa aplicable (se corresponde con la de la comunidad que queremos simular) / G - proyección del modelo de Gipuzkoa. Fuente: Elaboración propia.

las desviaciones en Bizkaia. La diferencia promedio entre precios inferiores y superiores es de $-8,26$ y 10,96 euros, respectivamente, que se incrementa hasta $-6,07$ euros para los primeros si excluimos a
Bizkaia del análisis. En todo caso, constatamos que los precios reales están por debajo de los sugeridos por Gipuzkoa: en torno a una media del $35 \%$ para grados o y II-III y en poco más del $11 \%$ para grados I.

\section{Proyección del modelo guipuzcoano: condiciones de implementación}

- Pese a que los precios en el resto del Estado permiten alcanzar mayores índices potenciales de beneficio, podemos afirmar que, en general, son insuficientes para llegar a los niveles de atención extrapolados desde el modelo de Gipuzkoa.

- Para que dichos niveles de atención sean de aplicación en otras comunidades, además de subir los precios para los diferentes grados de dependencia, es necesario incrementar las ratios, máxime cuando la Ley 39/2006 reconoce como preferentes los ingresos de grados II y III (IPD $\geq 2,5)$.

- La traslación del esquema guipuzcoano, aun cuando produce un efecto neto positivo en el precio del $64,4 \%$ de las casuísticas, afecta con diferente signo a cada grupo de coste. Así, proyecta incrementos para el personal y decrementos para el resto de costes, especialmente apreciables para grados II y III $\left(\Delta C P\right.$ medio $=16,27$ euros versus $\nabla G D+\nabla A+\nabla B^{\circ}=5,19$ euros). 
4.1. Adaptabilidad de la figura principal en la atención: ratios equivalentes de gerocultor/a

Somos conscientes de las dificultades implícitas en la proyección de estas ratios a otras realidades asistenciales, más o menos alejadas en fondo y forma del sistema vasco de servicios sociales. En todo caso, si fuéramos capaces de establecer algún tipo de correspondencia, tal vez podríamos cuantificar un factor corrector o factor de equivalencia de los tiempos del modelo guipuzcoano en otras comunidades. Por ejemplo, una equivalencia que contuviera relaciones cruzadas podría constituirse en un buen "traductor" de necesidades entre diferentes, siempre que se interpretara como axiomática una idéntica productividad por hora de trabajo -como, además, no cabría plantear de ninguna otra manera dada la presumible incoherencia de una demostración empírica en sentido contrariocualquiera que fuera el contexto de aplicación:

- Relación entre la ratio de auxiliar de geriatría de cada normativa y la ratio de Gipuzkoa (Decreto Foral 38/2007).

- Relación entre la jornada laboral anual de cada comunidad y la aplicable en Gipuzkoa.

La relación cruzada o potencia de la comunidad a valorar respecto del modelo guipuzcoano vendría determinada por la siguiente expresión, donde denotaremos cada variable como se indica:

$$
\mathrm{p}=\frac{\sum_{\mathrm{i}=1}^{\mathrm{i}=3} \mathrm{n}_{\mathrm{i}}{ }^{*} \mathrm{p}_{\mathrm{i}}}{\mathrm{n}}=\frac{\mathrm{n}_{1}{ }^{*} \mathrm{p}_{1}+\mathrm{n}_{2}{ }^{*} \mathrm{p}_{2}+\mathrm{n}_{3}{ }^{*} \mathrm{p}_{3}}{\mathrm{n}}
$$

- p: potencia media ponderada de un centro (en función del tamaño de cada estrato).

- $\mathrm{n}_{\mathrm{i}}$ : tamaño de cada estrato de dependencia (lógicamente, se cumplirá que $n=\Sigma n_{i}$ ).

- $\mathrm{p}_{\mathrm{i}}$ : potencia de cada estrato de dependencia respecto de la normativa guipuzcoana, calculada conforme a la relación $p_{i}=\frac{r_{i}}{r_{\text {eq.ref-i }}}$ $\left(r_{i}\right.$ : ratio del estrato i de la normativa destino y $r_{\text {eq.ref-i: }}$ ratio equivalente de Gipuzkoa para el estrato i), donde, a su vez,

$r_{\text {eq.ref-i }}=r_{\text {ref-i }} * \frac{J G}{J_{i}}$

$\left(r_{\text {refi: }}:\right.$ ratio de Gipuzkoa para el estrato

i, JG: jornada anual de Gipuzkoa y J: jornada anual en convenio colectivo de la comunidad/territorio j). El cálculo de $r_{\text {eq.refi. }}$ para cada centro se realizará acorde con la siguiente secuencia, en caso de inexistencia o indefinición de ratios por figuras

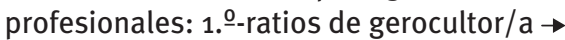
2.--ratios de atención directa $\rightarrow$ 3.-ratio total.

La potencia de una comunidad -si su normativa contuviera ratios de atención - o de un centro en particular -si se hubieran consensuado dichas ratios con la Administración Pública en ausencia de regulación pública aplicable- es la capacidad de recursos disponibles para satisfacer una necesidad. En nuestro sector, la disponibilidad de personal se mide en ratios o presencia de personal especializado por residente en tanto por uno. Sin embargo, este indicador deja de ser homogéneo en la medida que coexisten diferentes convenios colectivos con jornadas anuales específicas. Si expresamos la potencia como cociente entre ratio del contexto a adaptar y ratio de referencia (Gipuzkoa) y, además, lo hacemos en un sector con una productividad análoga cualquiera que fuera el contexto, dicha relación debería estar sujeta, a su vez, al número anual de horas trabajadas. Dicho de otro modo, dado que el Decreto 38/2007 de Gipuzkoa asigna tiempos (minutos por día) en función de perfiles de atención, la ratio de referencia para el perfil i se obtendría según la expresión

$r_{\text {ref-i }}=\frac{\left(m_{i} \times 365\right) / 60}{J G}$

$\left(m_{i}:\right.$ minutos por día para el perfil i y JG: jornada anual de 1.592 horas para el convenio colectivo de Gipuzkoa). De acuerdo con esta nueva identidad, la potencia de cada estrato i también adoptaría la siguiente expresión:

$$
\begin{aligned}
& p_{i}=\frac{r_{i}}{r_{\text {eq.ref-i }}}=\frac{r_{i}}{r_{\text {ref-i }} \times \frac{J G}{J_{i}}}=\frac{r_{i}}{\frac{\left(m_{i} \times 365\right) / 60}{J G} \times \frac{J G}{J_{i}}} \\
& p_{i}=\frac{r_{i}}{\frac{\left(m_{i} \times 365\right) / 60}{J_{i}}}
\end{aligned}
$$

\subsubsection{Adaptabilidad del modelo desde factores de equivalencia}

Nadie duda de la influencia que factores como el precio/plaza o la retribución bruta mensual básica para auxiliares de geriatría pudieran tener en la composición de las plantillas de personal. Asimismo, que la financiación pública sea suficiente depende intrínsecamente de la capacidad del centro para configurar sus colectivos profesionales. Nuestro modelo de proyección, sin embargo, debe abstraerse de dichas variables para centrar sus estimaciones en conceptos si cabe más homologables como, por ejemplo, las ratios de atención definidas en las respectivas normativas autonómicas, en definitiva la única manera objetiva de determinar recursos exigibles que no necesariamente suficientes (ayuda de tercera persona para la realización de las AVD o actividades de la vida diaria). Unas ratios que, por otra parte, deben ser transformadas en función de las jornadas anuales máximas previstas en los respectivos convenios colectivos. Es por ello que la Tabla 17 define ratios de auxiliar de geriatría por perfiles de atención o, en su defecto, ratios de atención directa o ratios de atención total; asimismo, se emparejan comunidades autónomas y convenios colectivos de aplicación. La acción combinada de ambas variables determina la relación entre la ratio de cada comunidad y la ratio de Gipuzkoa 
$\left(r_{i}=p_{i} \times r_{r e f-i} \times \frac{J G}{J_{i}}\right)$

que, además, discrimina tres niveles de atención directamente derivados del baremo BVD: autónomo (grado o), dependiente (grado I, niveles 1 y 2) y dependientes (grado II, niveles 1 y 2 y grado III, niveles 1 y 2 ).

En cualquier caso, relaciones obtenidas desde una supuesta correspondencia entre diferentes tipos de ratios deben ser contrastadas para comprobar el cumplimiento de hipótesis nulas. Para interpretar que las ratios de atención directa o atención total son buenos sustitutivos de la ratio de gerocultor/a, el promedio de la variable $\mathrm{p}$ (potencia autonómica) no debería presentar diferencias estadísticamente significativas para los dos pares de muestras posibles: ratios de gerocultor/a-ratios de atención directa y ratios de gerocultor/a-ratios totales. ¿Podemos rechazar, con un nivel de confianza del
$95 \%$, que la diferencia entre medias es nula? ¿O, si no es así, que la diferencia es debida al azar?

Realicemos un análisis descriptivo de las normativas que presentan pares de valores (ratio de gerocultor/a-ratio de atención directa o ratio de gerocultor/a-ratio total). Se constata que las potencias de los primeros valores de cada par (ratio de gerocultor/a) guardan un considerable paralelismo con los segundos (ratios de atención directa y total). Podríamos concluir que aquellas autonomías que detallan sus ratios lo hacen de tal modo que las potencias respecto de la ratio de referencia (Gipuzkoa) apenas presentan diferencias reveladoras en términos medios. En concreto, para los pares ratio de gerocultor/a-ratio de atención directa la potencia media se corresponde respectivamente con un $86 \%$ para las primeras y un $89 \%$ para las segundas; para combinaciones ratio de gerocultor/a-ratio total, se presentan sendas potencias del $89 \%$ y $72 \%$.

Tabla 17. Relaciones entre ratios de personal de cada normativa y Gipuzkoa $\left(r_{i}\right)$

\begin{tabular}{|c|c|c|c|c|c|c|c|c|c|}
\hline \multirow{3}{*}{ Autonomía } & \multicolumn{3}{|c|}{ Grado o } & \multicolumn{3}{|c|}{ Grado I } & \multicolumn{3}{|c|}{ Grados II y III } \\
\hline & \multirow{2}{*}{ Ratio } & \multicolumn{2}{|c|}{ Gipuzkoa } & \multirow{2}{*}{ Ratio } & \multicolumn{2}{|c|}{ Gipuzkoa } & \multirow{2}{*}{ Ratio } & \multicolumn{2}{|c|}{ Gipuzkoa } \\
\hline & & Ratio & Tipo & & Ratio & Tipo & & Ratio & Tipo \\
\hline \multirow{2}{*}{ Ratios de Gipuzkoa } & G & $A D$ & AT & G & AD & AT & $\mathbf{G}$ & AD & AT \\
\hline & 0,149 & 0,170 & 0,262 & 0,239 & 0,275 & 0,423 & 0,420 & 0,460 & 0,708 \\
\hline Andalucía 1997 & 0,125 & 0,149 & Gerocultor & 0,200 & 0,239 & Gerocultor & & & \\
\hline Andalucía 2007 & & & & 0,300 & 0,239 & Gerocultor & & & \\
\hline Andalucía (todos) & 0,100 & 0,149 & Gerocultor & 0,100 & 0,239 & Gerocultor & & & \\
\hline Araba & 0,163 & 0,170 & At. directa & 0,293 & 0,275 & At. directa & & & \\
\hline Aragón & 0,050 & 0,149 & Gerocultor & 0,200 & 0,239 & Gerocultor & & & \\
\hline Asturias & 0,120 & 0,149 & Gerocultor & 0,150 & 0,239 & Gerocultor & 0,275 & 0,420 & Gerocultor \\
\hline Bizkaia & 0,163 & 0,170 & At. directa & 0,293 & 0,275 & At. directa & & & \\
\hline Canarias & & & & & & & 0,275 & 0,420 & Gerocultor \\
\hline Cantabria & & & & 0,295 & 0,337 & At. directa & & & \\
\hline Castilla - La Mancha & 0,067 & 0,149 & Gerocultor & 0,167 & 0,239 & Gerocultor & & & \\
\hline Castilla y León & 0,219 & 0,170 & At. directa & 0,237 & 0,275 & At. directa & 0,292 & 0,708 & Total \\
\hline Cataluña & 0,250 & 0,262 & Total & 0,270 & 0,275 & At. directa & & & \\
\hline Extremadura & 0,050 & 0,149 & Gerocultor & 0,143 & 0,239 & Gerocultor & & & \\
\hline Galicia & 0,200 & 0,170 & At. directa & 0,350 & 0,275 & At. directa & & & \\
\hline Islas Baleares & 0,100 & 0,170 & At. directa & 0,300 & 0,239 & Gerocultor & & & \\
\hline La Rioja (1-40) & 0,195 & 0,149 & Gerocultor & 0,195 & 0,239 & Gerocultor & & & \\
\hline La Rioja (4-200) & 0,087 & 0,149 & Gerocultor & 0,087 & 0,239 & Gerocultor & & & \\
\hline La Rioja (>200) & 0,071 & 0,149 & Gerocultor & 0,071 & 0,239 & Gerocultor & & & \\
\hline La Rioja (desde 2017) & & & & 0,280 & 0,239 & Gerocultor & & & \\
\hline Madrid & 0,250 & 0,262 & Total & 0,350 & 0,423 & Total & & & \\
\hline Murcia & 0,100 & 0,170 & At. directa & 0,250 & 0,275 & At. directa & & & \\
\hline Navarra & 0,100 & 0,262 & Total & 0,350 & 0,423 & Total & & & \\
\hline Valencia & 0,033 & 0,149 & Gerocultor & 0,242 & 0,239 & Gerocultor & 0,306 & 0,420 & Gerocultor \\
\hline
\end{tabular}


Tabla 18. Ratios equivalentes y potencias

\begin{tabular}{|c|c|c|c|c|c|c|}
\hline \multirow{2}{*}{ Autonomía } & \multicolumn{3}{|c|}{$r_{\text {eq }}=r_{i}^{*} J_{i} / J G(*)$} & \multicolumn{3}{|c|}{ p (potencia autonómica) } \\
\hline & Grado o & Grado I & Grado II y III & Grado o & Grado I & Grado II y III \\
\hline Andalucía 1997 & 0,141 & 0,225 & 0,225 & $94 \%$ & $94 \%$ & $54 \%$ \\
\hline Andalucía 2007 & 0,107 & 0,338 & 0,338 & $72 \%$ & $141 \%$ & $80 \%$ \\
\hline Andalucía (todos) & 0,113 & 0,113 & 0,113 & $76 \%$ & $47 \%$ & $27 \%$ \\
\hline Araba & 0,183 & 0,329 & 0,329 & $108 \%$ & $120 \%$ & $72 \%$ \\
\hline Aragón & 0,056 & 0,225 & 0,225 & $38 \%$ & $94 \%$ & $54 \%$ \\
\hline Asturias & 0,135 & 0,169 & 0,310 & $91 \%$ & $71 \%$ & $74 \%$ \\
\hline Bizkaia & 0,173 & 0,312 & 0,312 & $102 \%$ & $113 \%$ & $68 \%$ \\
\hline Canarias & 0,107 & 0,215 & 0,310 & $72 \%$ & $90 \%$ & $74 \%$ \\
\hline Cantabria & 0,107 & 0,332 & 0,380 & $72 \%$ & $121 \%$ & $83 \%$ \\
\hline Castilla-La Mancha & 0,075 & 0,188 & 0,188 & $50 \%$ & $78 \%$ & $45 \%$ \\
\hline Castilla y León & 0,246 & 0,266 & 0,328 & $145 \%$ & $97 \%$ & $46 \%$ \\
\hline Cataluña & 0,281 & 0,304 & 0,304 & $107 \%$ & $110 \%$ & $66 \%$ \\
\hline Extremadura & 0,056 & 0,161 & 0,161 & $38 \%$ & $67 \%$ & $38 \%$ \\
\hline Galicia & 0,223 & 0,390 & 0,390 & $131 \%$ & $142 \%$ & $85 \%$ \\
\hline Islas Baleares & 0,113 & 0,338 & 0,338 & $66 \%$ & $141 \%$ & $80 \%$ \\
\hline La Rioja (1-40) & 0,218 & 0,218 & 0,218 & $146 \%$ & $91 \%$ & $52 \%$ \\
\hline La Rioja (4-200) & 0,098 & 0,098 & 0,098 & $66 \%$ & $41 \%$ & $23 \%$ \\
\hline La Rioja (>200) & 0,080 & 0,080 & 0,080 & $54 \%$ & $33 \%$ & $19 \%$ \\
\hline La Rioja (desde 2017) & 0,106 & 0,313 & 0,313 & $71 \%$ & $131 \%$ & $74 \%$ \\
\hline Madrid & 0,280 & 0,393 & 0,393 & $107 \%$ & $93 \%$ & $55 \%$ \\
\hline Murcia & 0,113 & 0,281 & 0,281 & $66 \%$ & $102 \%$ & $61 \%$ \\
\hline Navarra & 0,113 & 0,394 & 0,394 & $43 \%$ & $93 \%$ & $56 \%$ \\
\hline Valencia & 0,037 & 0,271 & 0,343 & $25 \%$ & $113 \%$ & $82 \%$ \\
\hline
\end{tabular}

(*) Ratios equivalentes corregidas por efecto combinado de ratio de Gipuzkoa y jornada anual máxima.

Fuente: Elaboración propia.

La descriptiva que analiza la proyección de datos desde las ratios de gerocultor/a o desde las ratios de atención directa o total es concluyente: en términos medios, la asimilación de potencias difiere en modo residual entre unas y otras. En todo caso, si sometemos la conclusión a pruebas de significación estadística de diferencia entre medias para muestras dependientes (los son en la medida que un mismo elemento presenta una dualidad de posibles valores) concluimos que se acepta la hipótesis nula al nivel de riesgo del $5 \%$ y se determina que entre ambas muestras no hay diferencia significativa y que, por tanto, las potencias calculadas desde las ratios de auxiliar de geriatría no difieren de las obtenidas desde las ratios de atención directa o total.

\subsubsection{Proyectando un caso real al conjunto de autonomías del Estado}

Analicemos la adaptabilidad del modelo guipuzcoano para cada factor $\mathrm{p}$ (potencia) propio de cada autonomía o, en su caso, unidad territorial competente (Araba y Bizkaia se desvinculan normativa de acreditación, los convenios colectivos que rigen cada territorio histórico son diferentes). Supongamos que la matriz de valoraciones de la dependencia conforme al índice Barthel-CIF presenta la distribución de la Tabla 19, incluidas las equivalencias a grupos de dependencia del Decreto 38/2007 de Diputación Foral de Gipuzkoa (grado o, grado I y grados II-III).

Como ya hemos indicado, Gipuzkoa asocia niveles de dependencia y, por ende, módulos de financiación a los grupos de dependencia del baremo BVD. Reducir las diferentes intensidades de ayuda para realizar todas las tareas implícitas en las AVD recogidas en el BVD no es sino agrupar distintas casuísticas bajo un mismo patrón. En definitiva, el propio baremo clasifica diferentes combinaciones de AVD e intensidad de ayuda de tercera persona para determinar grados de dependencia, un concepto que nos sugiere la idea de isogrupo u ordenación de los residentes en grupos homogéneos de consumo (tiempo de auxiliar) independientemente de su recorrido por el baremo de dependencia. No obstante, la tipificación de categorías de dependencia hace que perdamos perspectiva en la percepción afinada de las necesidades reales de atención residencial. La lógica asistencial nos confirma que no todas las persona integrantes de un mismo grupo tienen por qué necesitar el mismo nivel de ayuda para todas las AVD. En consecuencia, no deberíamos desestimar la posibilidad de correlacionar el BVD con otros baremos para preservar el detalle en los cuidados a las persona mayores. A tal efecto, el índice Barthel podría constituirse en un buen estimador de combinaciones AVD-ayuda de tercera persona. 
Tabla 19. Centro tipo para aplicación del método de adaptación

\begin{tabular}{|l|c|c|c|c|c|c|}
\hline Distribución Barthel-CIF & A & L & M & G & C & Total \\
\hline Módulo & 28 & 6 & 3 & 3 & 22 & 62 \\
\hline Alimentación & 14 & 5 & 2 & 10 & 31 & 62 \\
\hline Usar el retrete & 9 & 9 & 12 & 3 & 29 & 62 \\
\hline Deposición/Micción & 4 & 3 & 2 & 10 & 43 & 62 \\
\hline Higiene personal & 15 & 0 & 1 & 9 & 37 & 62 \\
\hline Acicalamiento & 12 & 1 & 1 & 12 & 36 & 62 \\
\hline Vestirse & 18 & 1 & 3 & 16 & 24 & 62 \\
\hline Transferencias & 5 & 5 & 15 & 3 & 34 & 62 \\
\hline Desplazamiento & 4 & 9 & 2 & 12 & 35 & 62 \\
\hline Mantenimiento salud & & & & & \\
\hline
\end{tabular}

Fuente: Elaboración propia.

\begin{tabular}{|l|c|c|c|}
\hline DF 38/2007 \\
\hline Concepto & Grado o & Grado I & Grados II y III \\
\hline Plazas & 1 & 11 & 50 \\
\hline Potencia & $94 \%$ & $94 \%$ & $54 \%$ \\
\hline
\end{tabular}

Trazar una buena correspondencia entre el BVD y el índice Barthel versión Shah para determinar niveles de dependencia constituye, en sí mismo, el fundamento sobre el que soportar la adaptabilidad del modelo a otros contextos. Como contrapunto, las comunidades autónomas más prolijas en la definición de ratios nunca contemplan más de tres grupos de dependencia. En cualquier caso, ¿dónde fijamos la frontera que separa la dependencia de la gran dependencia? Izagirre y Calvo (Zahartzaroa, 2014) estiman que se sitúa en los 80 puntos Barthel (resultados satisfactorios en las pruebas de independencia desde la variable chi cuadrado). Por su parte, en la interpretación sugerida por el propio Shah para graduar el índice Barthel, quizá fuera más acertado disociar en 90 puntos ambos estados de necesidad de tercera persona (0-90, dependencia total, severa o moderada / 91-99: dependencia escasa / 100: independencia).

Simulemos los resultados de la adaptación desde la definición de factores p para cada autonomía. Recordemos que la relación entre las ratios de las diferentes autonomías y Gipuzkoa se cuantifica según los criterios del punto 4.1.1., "Adaptabilidad del modelo desde factores de equivalencia". En una primera aproximación, ajustaremos las relaciones entre ratios siguiendo la secuencia gerocultor/a $\rightarrow$ atención directa $\rightarrow$ atención total porque no podemos rechazar la hipótesis nula. Para los más puristas, sin embargo, se han simulado tiempos basados exclusivamente en las ratios de gerocultor/a: si la normativa especifica las mismas, la relación con Gipuzkoa es inmediata; si no lo hace, interpretaremos que se corresponde con la media estatal, incluida Gipuzkoa. Se comprueba que en la mayoría de los casos la media del sector estima menores tiempos que aquellos derivados de la adaptación a ratios de atención directa o ratios totales en la secuencia anteriormente descrita y que, en consecuencia, no constituye una alternativa verosímil (desviación estatal media del 13,99\% para el ejemplo simulado). Sin embargo, condicionar la asignación de ratios a la media del sector podría "castigar" o "premiar" dependiendo de las relaciones $r_{i}$ y de la concentración de valoraciones en los perfiles de grado o, grado I y grados II-III. Un método tan indiscriminado entra en conflicto con el Acuerdo sobre criterios comunes de acreditación para garantizar la calidad de los centros y servicios del Sistema para la Autonomía y la Atención a la Dependencia (SAAD), de 27 de noviembre de 2008 (BOE, 17/12/2008). Un acuerdo de un órgano creado al amparo de la Ley 39/2006 que "no constituye una auténtica fuente del Derecho y, por lo tanto, su contenido es de una más que dudosa exigibilidad jurídica” (Molina, 2010). Sin embargo, salvando las dudas, el acuerdo pretende el establecimiento de unas ratios de atención global y, asimismo, de ratios específicas para la categoría de cuidador/a, gerocultor/a o similar, exigibles desde diciembre de 2015. En concreto, ambas ratios distinguen grados de dependencia en la siguiente medida:

\begin{tabular}{|c|c|}
\hline \multicolumn{2}{|c|}{ Ratios globales } \\
\hline $\begin{array}{c}\text { Dependencia } \\
\text { grado II }\end{array}$ & $\begin{array}{c}\text { Dependencia } \\
\text { grado III }\end{array}$ \\
\hline 0,45 & 0,47 \\
\hline
\end{tabular}

\begin{tabular}{|c|c|}
\hline \multicolumn{2}{|c|}{ Ratios de gerocultor/a } \\
\hline $\begin{array}{c}\text { Dependencia } \\
\text { grado II }\end{array}$ & $\begin{array}{c}\text { Dependencia } \\
\text { grado III }\end{array}$ \\
\hline 0,27 & 0,28 \\
\hline
\end{tabular}

El Consejo Territorial es el ente responsable y competente para la fijación de ratios (artículo 34.2 de la Ley 39/2006), limitados en la actualidad al personal total y al que ejercita tareas auxiliares de cuidado y atención para ir incorporando progresivamente nuevas figuras profesionales. En consecuencia, dada la definición explícita de ratios totales, parece que lo más adecuado es adaptar el modelo conforme a estos si las normativas autonómicas no expresan ratios de gerocultor/a. Con esta medida, el modelo adaptado cumple un doble objetivo: respetar las normas emanadas desde órganos competentes y correlacionar las plantilla de personal gerocultor a las propias ratios de cada comunidad autónoma.

El centro tipo presenta un índice IPD de 2,79 puntos. Para este nivel promedio de dependencia, Gipuzkoa procura mayor número de horas que cualquier otra comunidad, una vez corregidos los efectos producidos por la jornada laboral anual (Tabla 20). Galicia se aproxima desde ratios de atención directa que superan las guipuzcoana para grados o y l y que, aun manteniendo su posición, la alejan sustancialmente cuando el IPD promedio alcanza su máximo valor. Vuelve a tomar forma concreta una idea que hemos defendido de modo recurrente a lo largo del estudio: Gipuzkoa plantea incrementos progresivos de personal por encima 
del resto del Estado conforme aumenta el índice ponderado de dependencia (IPD) y no por ello el precio reacciona para garantizar mayores márgenes de beneficio. Como hemos pretendido demostrar, Gipuzkoa acompasa las plantillas de personal a las necesidades de atención y lo hace desde la construcción analítica del coste por plaza. Ello no significa que el modelo guipuzcoano se constituya en arquetipo de nada pero sí, tal vez, en referencia para equilibrar precios, perfiles de atención y costes.

Tabla 20. Adaptación para cada autonomía del centro tipo

\begin{tabular}{|l|l|l|l|}
\hline \multicolumn{4}{|l|}{ Datos de entrada } \\
\hline - Matriz de valoraciones del índice Barthel (Tabla 19) \\
\hline \multirow{2}{*}{ Dependencia } & Grado o & Grado I & Grados II y II \\
\cline { 2 - 5 } & 1 & 10 & 50 \\
\hline
\end{tabular}

(*) Tiempos obtenidos desde estudio realizado por Lares Euskadi como consecuencia del modelo teórico publicado en Zerbitzuan, 57 (diciembre, 2014).

Fuente: Elaboración propia.

\begin{tabular}{|l|c|c|}
\hline Contexto & Potencia & Horas totales para centro tipo (*) \\
\hline Gipuzkoa & & 41.909 \\
\hline Andalucía 1997 & $61,4 \%$ & 27.147 \\
\hline Andalucía 2007 & $91,0 \%$ & 38.467 \\
\hline Andalucía (todos) & $31,2 \%$ & 11.925 \\
\hline Araba & $80,7 \%$ & 34.510 \\
\hline Aragón & $60,5 \%$ & 26.797 \\
\hline Asturias & $73,4 \%$ & 31.721 \\
\hline Bizkaia & $76,4 \%$ & 32.892 \\
\hline Canarias & $61,4 \%$ & 32.919 \\
\hline Cantabria & $76,7 \%$ & 37.751 \\
\hline Castilla - La Mancha & $50,7 \%$ & 23.057 \\
\hline Castilla y León & $56,9 \%$ & 25.417 \\
\hline Cataluña & $74,6 \%$ & 32.189 \\
\hline Extremadura & $43,4 \%$ & 20.246 \\
\hline Galicia & $95,7 \%$ & 40.273 \\
\hline Islas Baleares & $90,9 \%$ & 38.431 \\
\hline La Rioja (>200) & $22,1 \%$ & 8.455 \\
\hline La Rioja (2017) & $84,4 \%$ & 35.938 \\
\hline Madrid & $62,9 \%$ & 27.718 \\
\hline Murcia & $68,5 \%$ & 29.874 \\
\hline Navarra & $62,1 \%$ & 27.399 \\
\hline & Total & 6690 \\
\hline
\end{tabular}

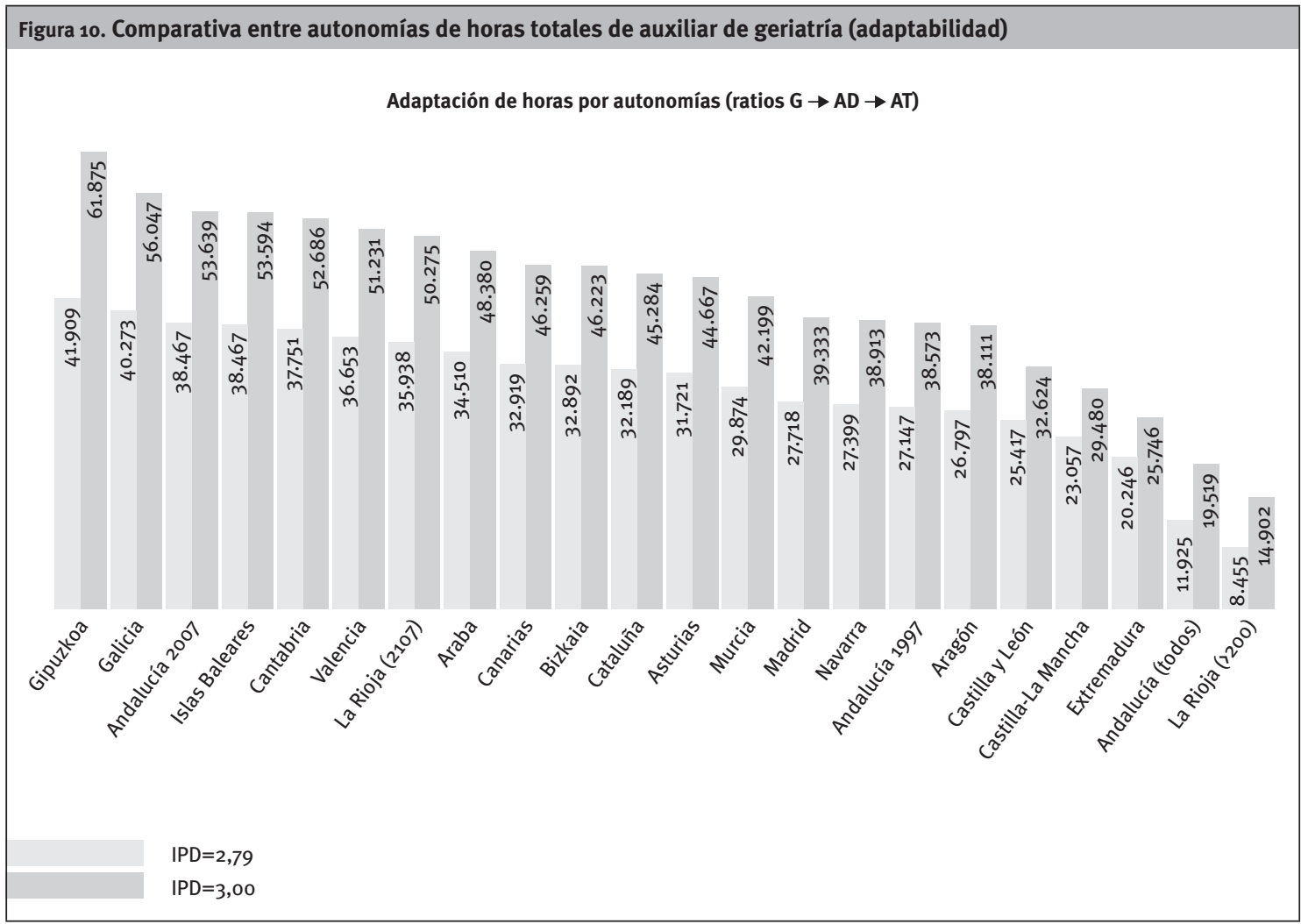

Fuente: Elaboración propia. 


\section{Conclusiones}

Además de las ideas enunciadas en la parte final de cada capítulo tratado, cabría considerar las siguientes conclusiones de carácter general que asimismo derivan en una serie de recomendaciones en la gestión pública del sector:

- La dispersión es una realidad incuestionable que vulnera el principio de solidaridad interterritorial desde muy diversas perspectivas. El panorama estatal, absolutamente divergente, está muy lejos de compartir cualquier enfoque sobre el paradigma actual en la atención residencial a personas mayores. No ha sido objeto de este estudio pronunciarse al respecto ni, por supuesto, defender la implantación de ninguna estrategia orientada a homogeneizar modelos en la prestación de servicios. Solo pretende describir el nivel de correspondencia entre perfiles de atención y recursos necesarios propuesto por cada normativa que, por otra parte, irremediablemente coloca a cada Administración en una determinada posición respecto de las demás.

- Si el panorama estatal fuera totalmente coincidente con el descrito en el estudio, solo desde nueve normativas - aquellas que especifiquen precios y ratios totales para dependientes y no dependientes- se podría acceder a una comparativa directa para escenarios de personal generalmente admitidos (Gipuzkoa, Andalucía-1997, Andalucía-todos, Araba, Aragón, Bizkaia, Castilla y León, Cataluña y Navarra). Para el resto, el contraste debe realizarse desde una supuesta relación entre las plantillas de atención directa e indirecta.

- La dispersión observada aconsejaría efectuar un seguimiento periódico y planificado de la evolución del sector desde organismos supracomunitarios como, por ejemplo, el Observatorio de la Dependencia. En todo caso, visto el grado de implantación autonómica de la Ley 39/2006, es difícilmente creíble que nuestro sector sea una excepción a la regla. Solo desde una voluntad política seria y consecuente podrían acortarse las actuales diferencias asistenciales, siempre y cuando se defienda pública y explícitamente que la atención estandarizada es un derecho de las personas mayores que conviven en un mismo contexto sociopolítico

- La definición cualitativa y cuantitativa de la dependencia debería ser común y generalmente extendida y, a su vez, estar biunívocamente relacionada con el precio. Cualquier otra alternativa reforzaría la dispersión e impediría una comparación intercomunitaria homogénea.

- La identificación de perfiles de atención con arreglo a baremos oficiales en el Estado constituiría una exigencia de implantación inmediata. Por añadidura, conseguiríamos superar clasificaciones anacrónicas de la dependencia y avanzaríamos en el diseño de modelos que garantizaran una correlación equilibrada entre las necesidades de las personas usuarias y los recursos destinados para satisfacer las mismas. En este sentido, indicadores similares al índice ponderado de dependencia (IPD) ayudarían a interpretar las diferencias intercomunitarias.

- Abandonar la dualidad autonomía-dependencia como únicos atributos para determinar la intensidad de ayuda de tercera persona en las AVD abre la posibilidad de tipificar los diferentes perfiles de usuario consecuentemente con la evolución de atención experimentada por el sector. Incluso la propia graduación del BVD, sobre todo para los grados II y III, debería ser desgranada en su composición para ajustar con más detalle las necesidades reales de atención (sirva como referencia el estudio de Lares "Euskadi sobre tiempos de auxiliar de geriatría", Zerbitzuan, 57).

- El coste por plaza $-y$, en consecuencia, el precio público-debería ser resultado del análisis de cada una de las partes modulares que lo componen y no efecto directo o indirecto de la disponibilidad presupuestaria negociada en términos políticos. Si entendemos el precio como aquel valor que garantiza el cumplimiento de los requisitos en normativa que, por su parte, dotan de los recursos necesarios para atender dignamente (costes), la correspondencia entre ambas variables debería ser estable cualquiera que fuera el nivel de dependencia. Hemos demostrado el incumplimiento de esta hipótesis porque, precisamente, una variable (precio) no es consecuencia de la otra (coste). La simulación de costes teóricos desde la interpretación de las diferentes normativas constata un hecho recurrente más que probable en la realidad: el precio y los costes podrían no guardan proporcionalidad alguna en dos tercios de las comunidades autónomas.

- La Diputación Foral de Gipuzkoa, entidad competente en la regulación de los servicios residenciales para personas mayores en el citado territorio foral, es una Administración Pública que se caracteriza por modular el coste de los servicios, asociar precios y ratios conforme a grados del BVD y financiar las plazas concertadas con umbrales de rentabilidad limitados pero suficientes para garantizar la sostenibilidad económica de los centros, si no se exigen cumplimientos por encima de lo establecido en normativa. Otras comunidades, con precios sensiblemente menores pero normativas ostensiblemente más laxas, pueden alcanzar beneficios superiores en detrimento de un mayor número de horas totales de atención. Ambas alternativas, igualmente válidas y respetuosas con la legalidad vigente, muestran cuál es el posicionamiento -casi deontológicoque defiende cada autonomía en la atención profesionalizada a las personas mayores en residencias. 
- Una hipotética homogeneización del sector pasaría por conjugar con inteligencia las estrategias aplicables en un Estado que debe transferir competencias en materia de servicios sociales a las comunidades autónomas. Para superar la dispersión actual -si se declarase un objetivo político en este sentido- los responsables políticos deberían actuar con fundamentos propios del benchmarking y no exponer las reivindicaciones en constante referencia a la diferencia de precios que, por otra parte, son reflejo del contexto socieconómico de cada autonomía (salarios e índice de coste de la vida) y del ideario asistencial defendido por cada ejecutivo autonómico. 


\section{Bibliografía referenciada}

CALVO F. (1990): Estadística aplicada, Ediciones Deusto.

COSTA A.; et al. (2015): Estimació de les paritats de poder adquisitiu per a les comunitats autònomes españoles, Monografies, 17, Generalitat de Catalunya-Departament d'Economia i Coneixement.

DÍAZ DÍAZ, B. (2012): “Estimación del coste de la atención a la dependencia en centros residenciales y de atención diurna o nocturna”, Zerbitzuan, 52, Gobierno Vasco.

FRESNO J.M.; et al. (2017): Cooperación público privada en el ámbito de las personas mayores y dependientes: requisitos para la puesta en marcha de centros y servicios, Lares Federación.

GÓMEZ ORDOKI, A. (2001): Sistema modular de costes y financiación en centros residenciales, GIZARTEKINTZA-Diputación Foral de Gipuzkoa

- (2014): "Valoración de la carga de trabajo de auxiliar en residencias para personas mayores (primera parte: modelo teórico)", Zerbitzuan, 57, Gobierno Vasco.

- (2017): MORETAG: Modelo referencial de asignación de tiempos de auxiliar de geriatría, Lares Euskadi.

GUADALAJARA OLMEDA, N. (1996): Análisis de costes en centros residenciales, Documentos técnicos del Imserso.
MOLINA SCHMID, A. (2010): Los requisitos de acreditación de residencias para personas mayores. Normativas autonómicas sobre ratios y formación mínima del personal para residencias privadas para personas mayores. Lares Federación.

MONTSERRAT CODORNIU, J. (2005): Coste de las residencias asistidas de mayores, SQS S.L.

RUBIERA MOROLLÓN F.; LASARTE NAVAMANUEL, E.; y FERNÁNDEZ VÁZQUEZ, E. (2013): “La economía de las regiones españolas en la crisis", Papeles de Economía Española, Funcas.

TORTOSA CHULIÁ, M.A.; FUENMAYOR FERNÁNDEZ, A.; y GRANELL PÉREZ, R. (2013): Estimación de los costes y revisión de la financiación de las residencias de mayores. LARES Comunidad Valenciana 2013, Universidad de Valencia-Lares Comunidad Valenciana.

- (2013): Evaluación de costes y financiación de las residencias de mayores. El sector no lucrativo en la Comunidad Valenciana, Universidad de Valencia-Lares Comunidad Valenciana.

VV.AA. (2016): La situación de los centros residenciales para personas mayores en Gipuzkoa, Centro de Documentación y Estudios SIIS - Dokumentazio eta Ikerketa Zentroa. 